SUPPORTING INFORMATION FOR:

\title{
Close-Packed Spherical Morphology in an ABA Triblock Copolymer Aligned with Large Amplitude Oscillatory Shear
}

Shu Wang, ${ }^{1}$ Renxuan Xie, ${ }^{2}$ Sameer Vajjala Kesava, ${ }^{2}$ Enrique D. Gomez, ${ }^{2}$ Eric W. Cochran, ${ }^{3}$ Megan L. Robertson ${ }^{1 *}$

\footnotetext{
${ }^{1}$ Department of Chemical and Biomolecular Engineering, University of Houston

${ }^{2}$ Department of Chemical Engineering and the Materials Research Institute, The Pennsylvania State University

${ }^{3}$ Department of Chemical and Biological Engineering, Iowa State University
}

*Corresponding author

4726 Calhoun Road

S222 Engineering Building 1

University of Houston

Houston, TX 77204-4004

mlrobertson@uh.edu

713-743-2748 


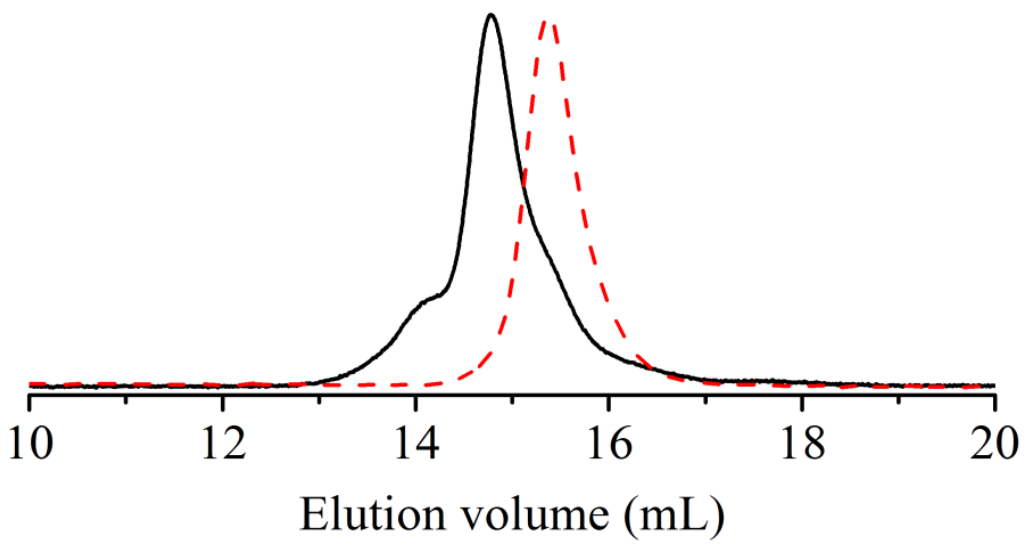

Figure S1: GPC refractometer data obtained for the SAS triblock copolymer (black solid curve). Data is also shown for the poly(lauryl acrylate-co-stearyl acrylate) random copolymer (red dashed curve) which was chain extended through addition of the polystyrene blocks to form the SAS triblock copolymer. 


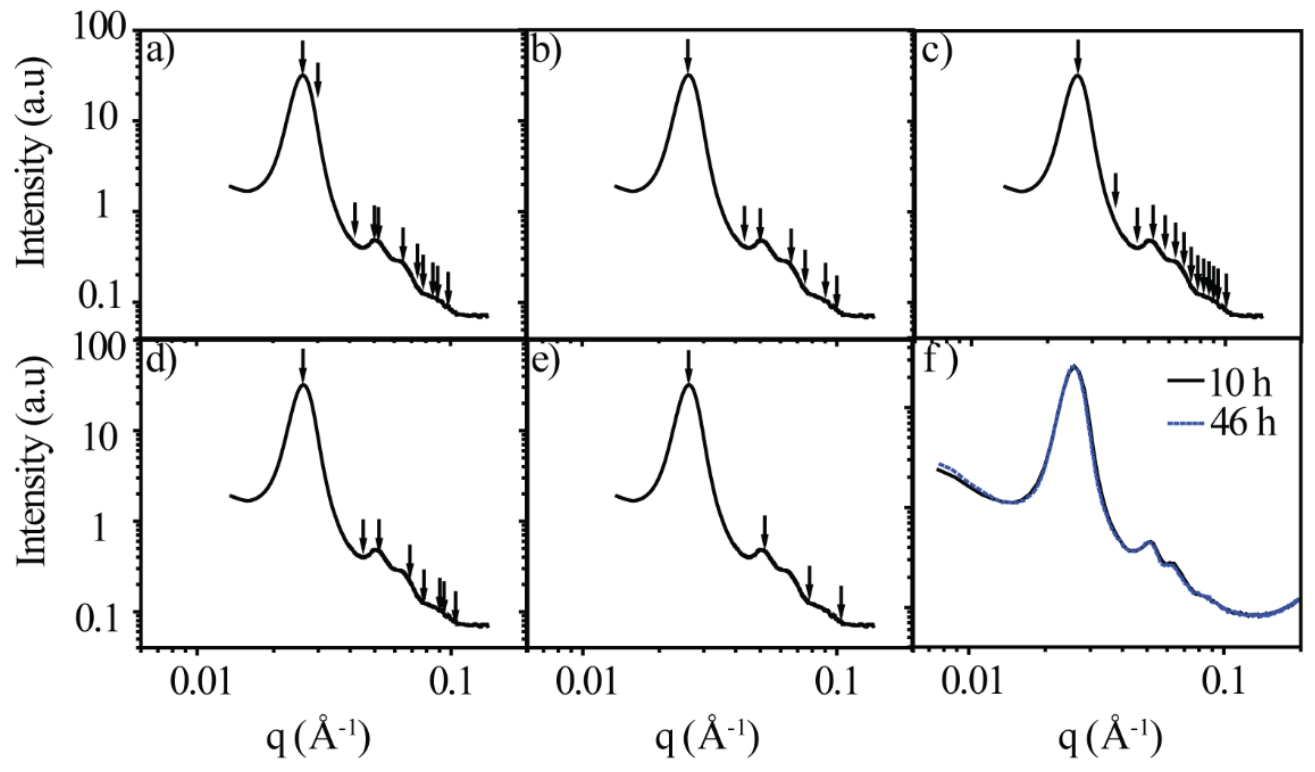

Figure S2: 1D SAXS pattern for the SAS triblock copolymer following compression molding, with predications for commonly observed block copolymer morphologies. a) FCC spheres; b) HCP spheres; c) BCC spheres; d) HCP cylinders; e) lamellae. In f), data were obtained after 10 and 46 $\mathrm{h}$ of annealing at $130{ }^{\circ} \mathrm{C}$ (after compression molding). In a) to e): the primary scattering peak maximum was observed at $\mathrm{q}=0.026 \AA^{-1}$ and three higher order scattering peak maxima were observed at $0.051,0.064$, and $0.086 \AA^{-1}$, respectively. In f): the primary scattering peak maximum was observed at $\mathrm{q}=0.026 \AA^{-1}$ and three higher order scattering peak maxima were observed at $0.051,0.062$, and $0.085 \AA^{-1}$, respectively 


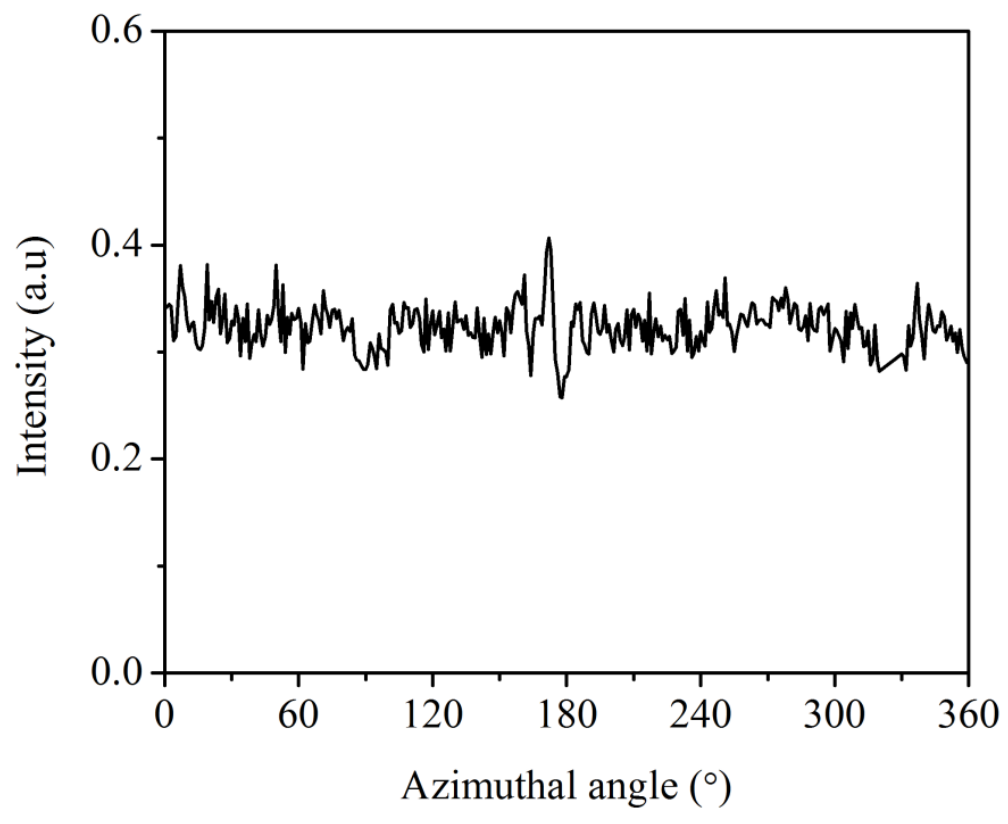

Figure S3: Intensity as a function of azimuthal angle of the primary scattering ring for the specimen before alignment (following compression molding). 


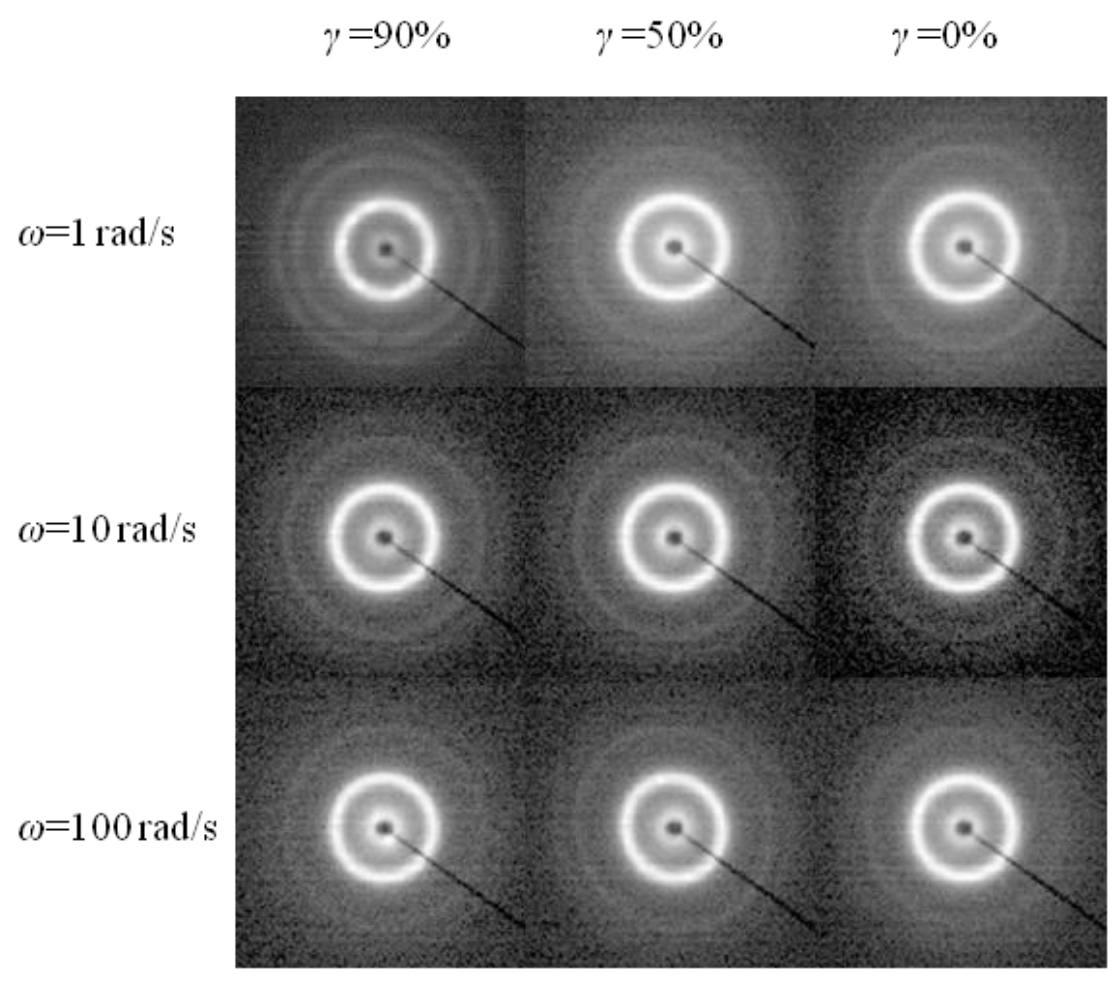

Figure S4: 2D SAXS data obtained in the shear gradient direction, after LAOS at $210{ }^{\circ} \mathrm{C}$ (strain $=100 \%)$. Data were obtained using various frequencies, $\omega(1,10$ and $100 \mathrm{rad} / \mathrm{s})$ as well as various sample positions corresponding to different local strain values (labeled as $\gamma$ on the figure). 


$$
\gamma=90 \% \quad \gamma=50 \% \quad \gamma=0 \%
$$

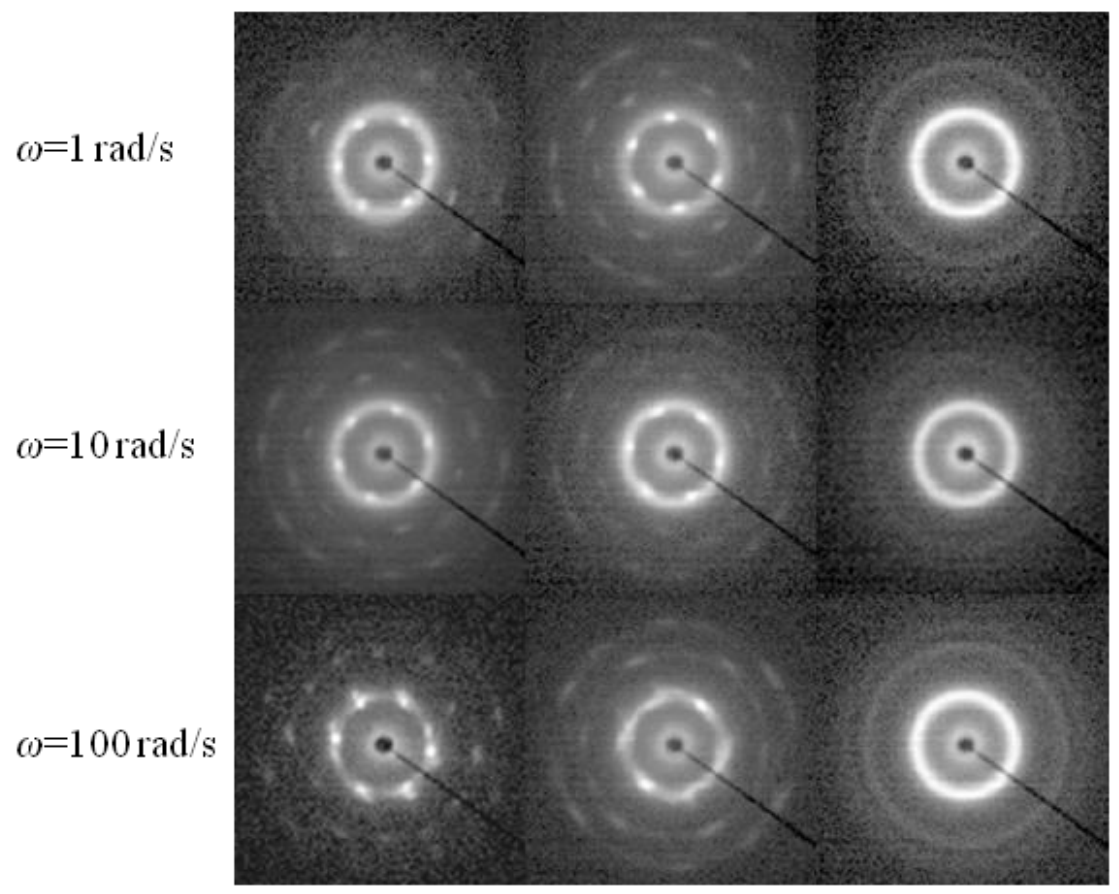

Figure S5: 2D SAXS data obtained in the shear gradient direction, after LAOS at $180{ }^{\circ} \mathrm{C}$ (strain $=100 \%)$. Data were obtained using various frequencies, $\omega(1,10$ and $100 \mathrm{rad} / \mathrm{s})$ as well as various sample positions corresponding to different local strain values (labeled as $\gamma$ on the figure). 
a)

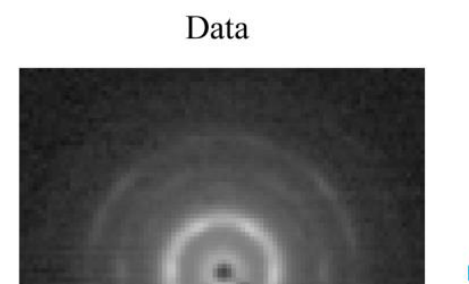

$\gamma=32 \%$

$\gamma=48 \%$

$\gamma=64 \%$

$\gamma=80 \%$
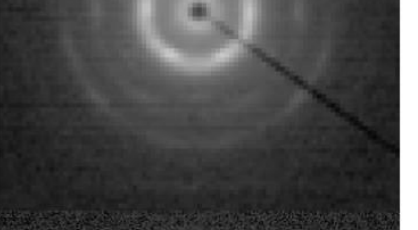

P

ㅁ $\Delta \square \Delta \square$

ㅁ $\Delta \square \square$

드뭉

$\triangle \square \square \Delta$

ㅁ $\triangle$ 口 $\square$

口 $\Delta$ 口 $\square \Delta \square$

$\triangle$ 口 口 $\Delta$

$\Delta \square \square \Delta \square$

口 $\triangle \Delta \square \square$

ㅁㅁ읍

$\Delta \square \square \Delta$

ㅁ $\triangle$ 口 $\square$

ㄷ口 $\triangle \Delta \Delta \square$

$\triangle \square \square \square \square \Delta$

$\Delta$ ㅁ $\Delta \Delta$

口 $\triangle A \square \square$

$\Delta \square$ 당

$\triangle \square \square \quad \boldsymbol{\Delta}$

ㅁ $\Delta$ 口

ㅁ口 ㅁ $\Delta \square$

$\triangle \square \square$

ㅁ $\triangle \Delta$

$\Delta \square \square \Delta \square$

口 $\Delta$ 口 口
$\Delta$ 口
Overlay

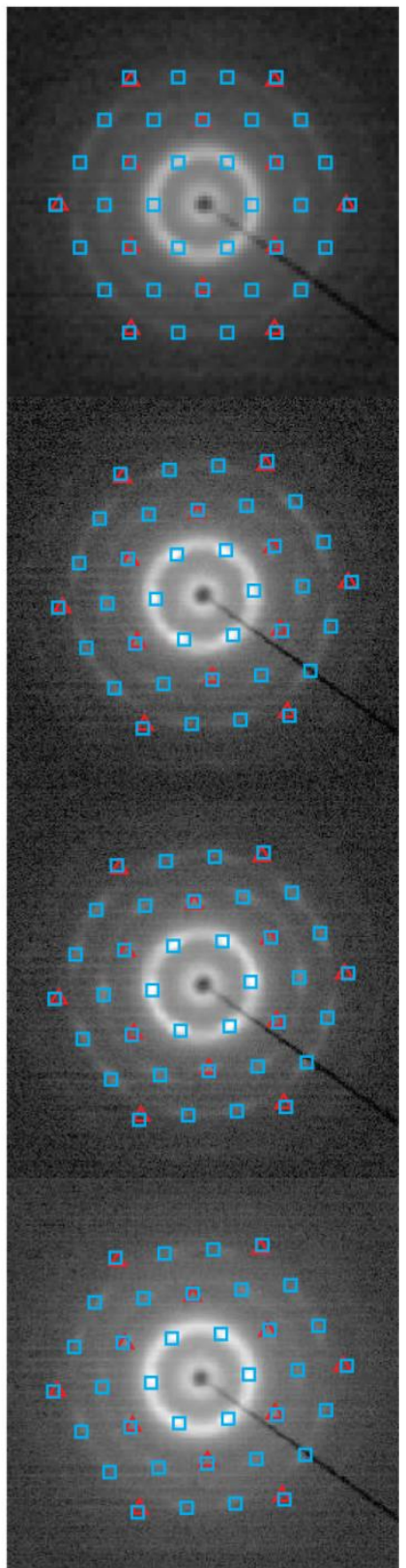

Figure S6a: Comparison of 2D SAXS data obtained in the shear gradient direction after LAOS at $180{ }^{\circ} \mathrm{C}$ at various local strain values, $\gamma$ (maximum strain $=100 \%$, frequency $=1 \mathrm{rad} / \mathrm{s}$ ), and patterns predicted for coexisting FCC spheres (red $\Delta$ ) and HCP spheres (blue $\square$ ). In the prediction of FCC spheres, the unit cell is aligned such that the shear gradient direction is parallel to the [111] direction along the unit cell. In the prediction of HCP spheres, the unit cell is aligned such that the shear gradient direction is parallel to the [0001] direction along the unit cell. The unit cell dimension used in the theoretical prediction was $\mathrm{a}=42 \mathrm{~nm}$ for FCC and $\mathrm{a} / \mathrm{c}=0.612, \mathrm{c}=47.2 \mathrm{~nm}$ for HCP. 


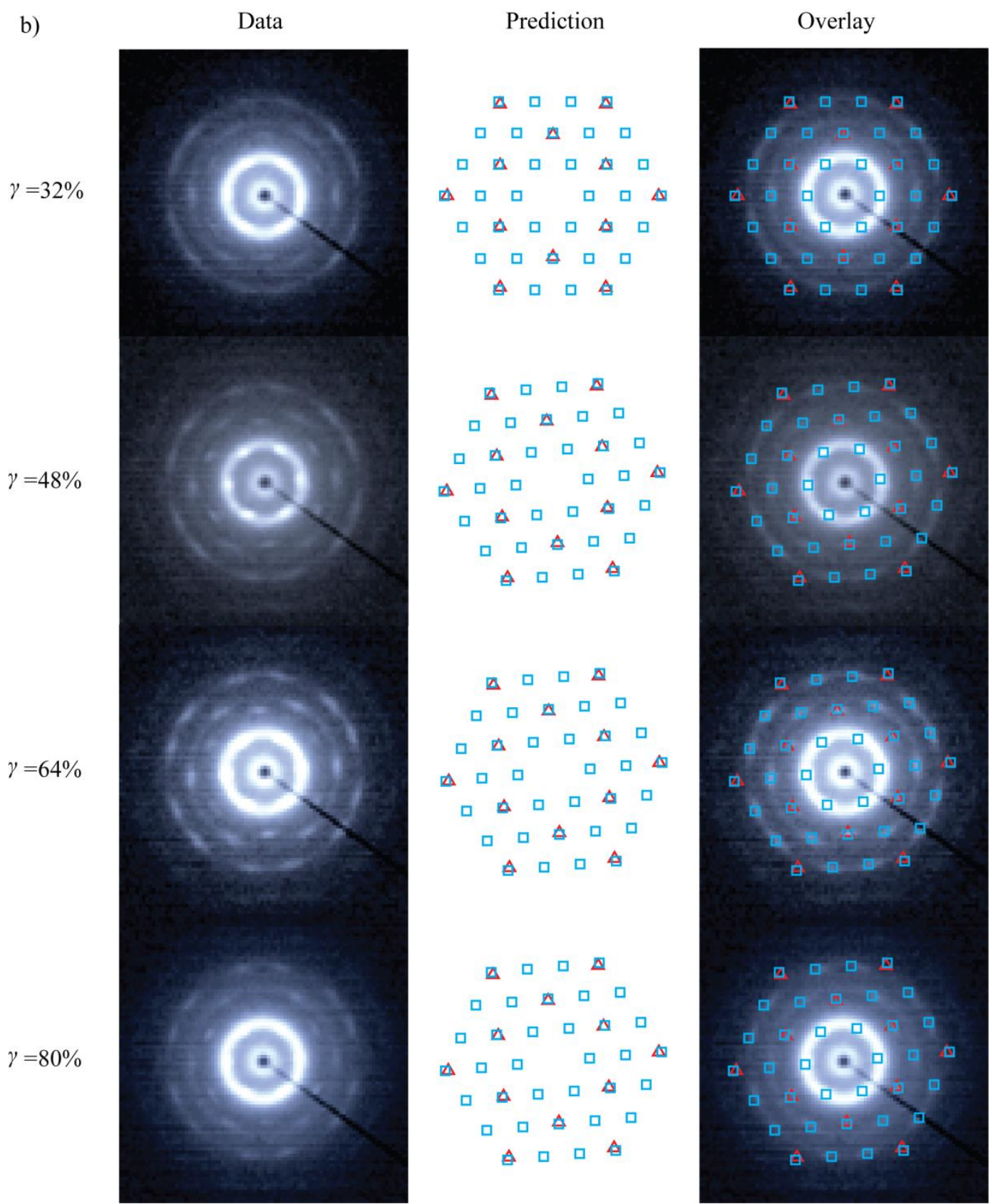

Figure S6b: Comparison of 2D SAXS data obtained in the shear gradient direction after LAOS at $180{ }^{\circ} \mathrm{C}$ at various local strain values, $\gamma$ (maximum strain $=100 \%$, frequency $=1 \mathrm{rad} / \mathrm{s}$ ), and patterns predicted for coexisting FCC spheres (red $\Delta$ ) and HCP spheres (blue $\square$ ). In the prediction of FCC spheres, the unit cell is aligned such that the shear gradient direction is parallel to the [111] direction along the unit cell. In the prediction of HCP spheres, the unit cell is aligned such that the shear gradient direction is parallel to the [0001] direction along the unit cell. Here in part b), the contrast is modified to improve the visibility of the higher order diffraction spots. The unit cell dimension used in the theoretical prediction was $\mathrm{a}=42 \mathrm{~nm}$ for FCC and $\mathrm{a} / \mathrm{c}=0.612, \mathrm{c}=47.2 \mathrm{~nm}$ for HCP. 


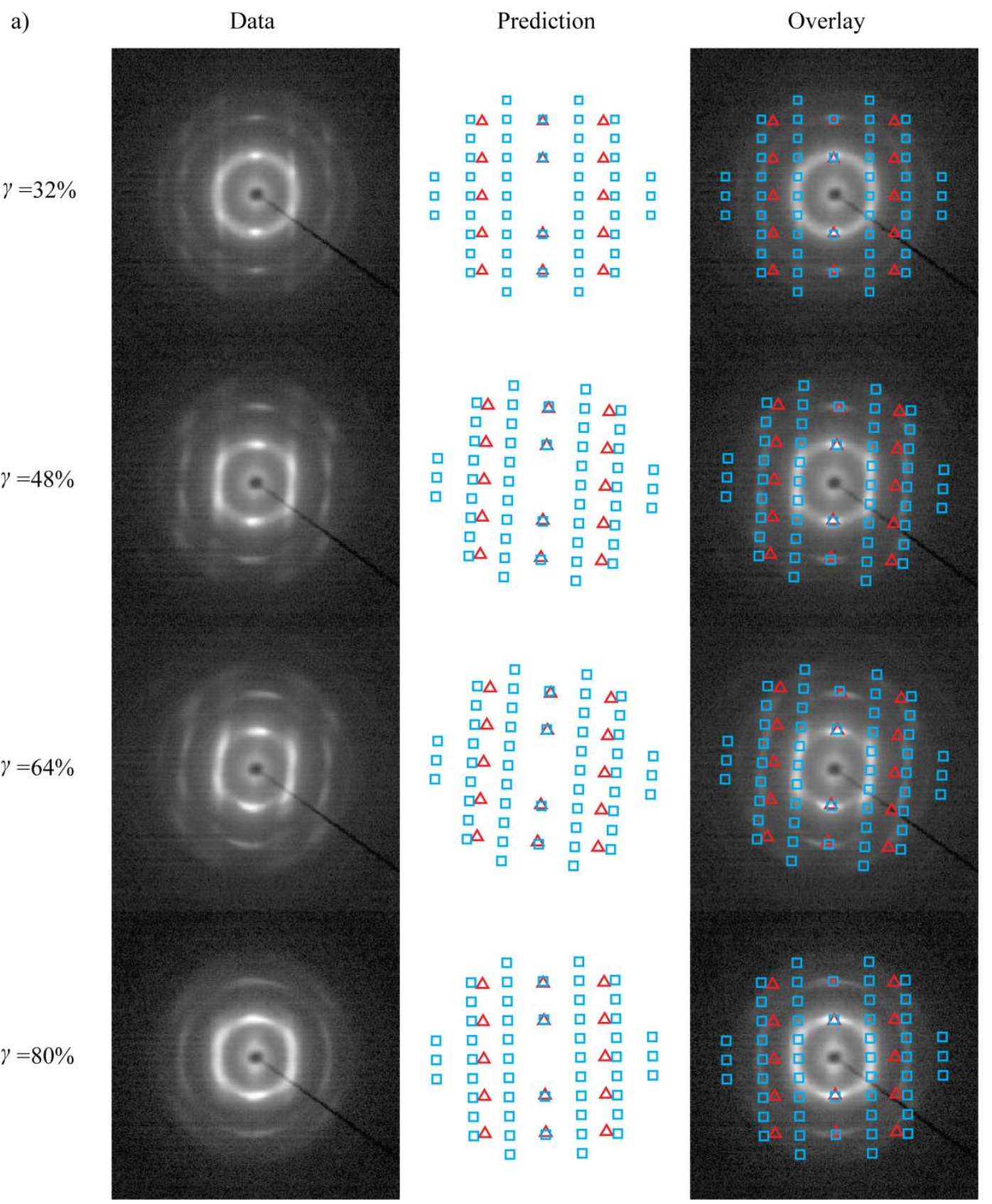

Figure S7a: Comparison of 2D SAXS data obtained in the velocity direction after LAOS at $180{ }^{\circ} \mathrm{C}$ at various local strain values, $\gamma$ (maximum strain $=100 \%$, frequency $=1 \mathrm{rad} / \mathrm{s}$ ), and patterns predicted for coexisting FCC spheres (red $\Delta$ ) and HCP spheres (blue $\square$ ). In the prediction of FCC

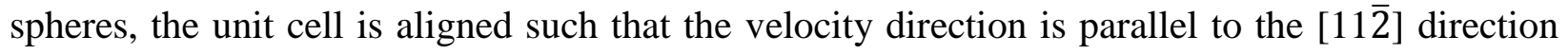
along the unit cell. In the prediction of HCP spheres, the unit cell is aligned such that the velocity direction is parallel to the [2110] direction along the unit cell. The unit cell dimension used in the theoretical prediction was $\mathrm{a}=42 \mathrm{~nm}$ for $\mathrm{FCC}$ and $\mathrm{a} / \mathrm{c}=0.612, \mathrm{c}=47.2 \mathrm{~nm}$ for HCP. 
b)

Data

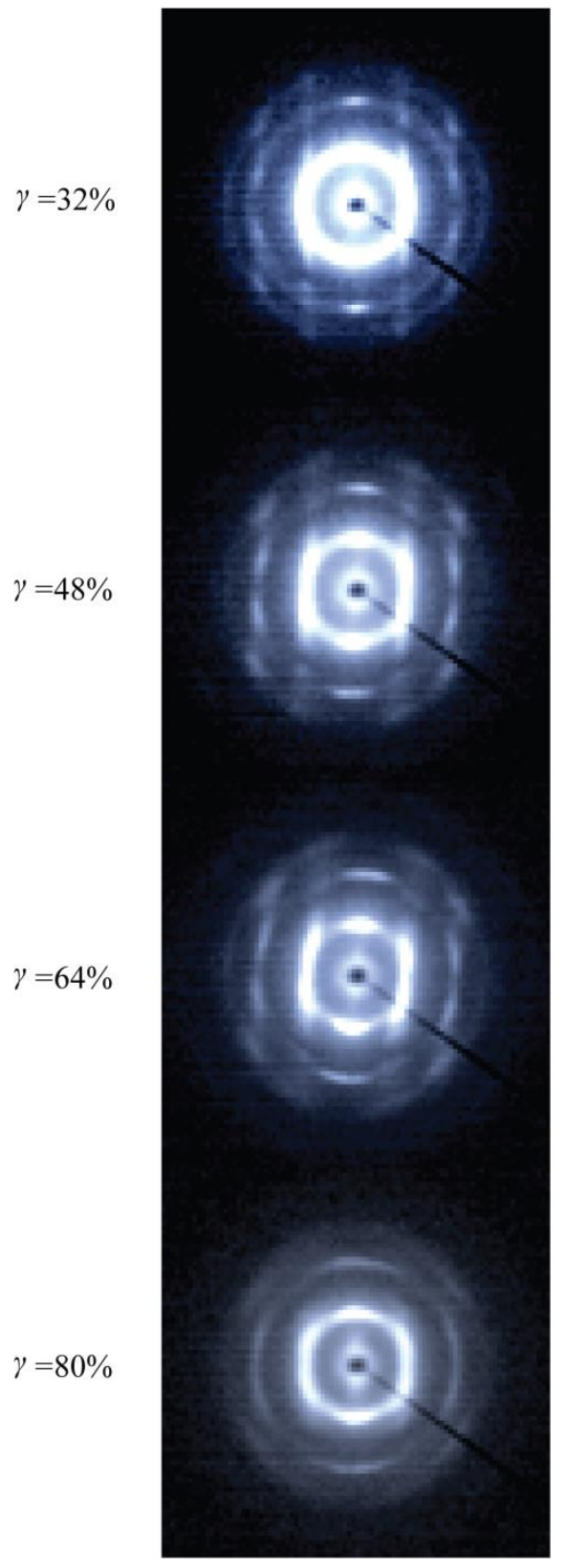

Prediction

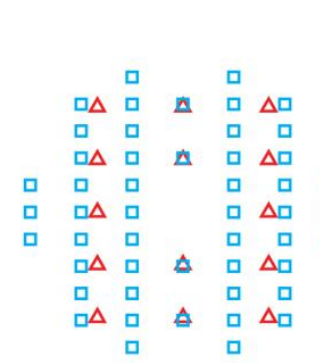

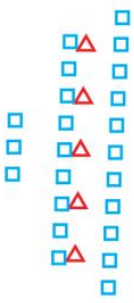
$\triangle \quad \square$ $\triangle \square \Delta$

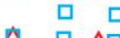
$\Delta \quad \square \Delta$ 모 ㅁㅁ $\Delta \quad \square \Delta \square$ A 무 $\quad$ ㅁ
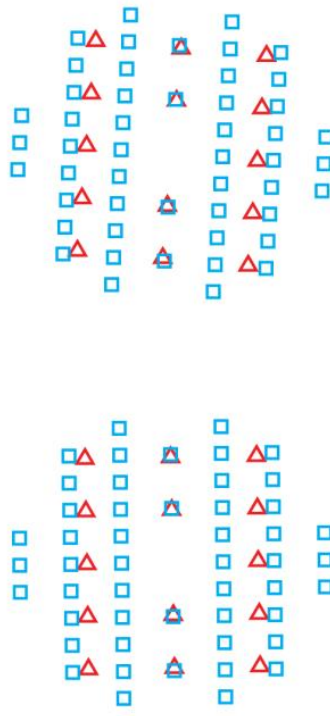

Overlay

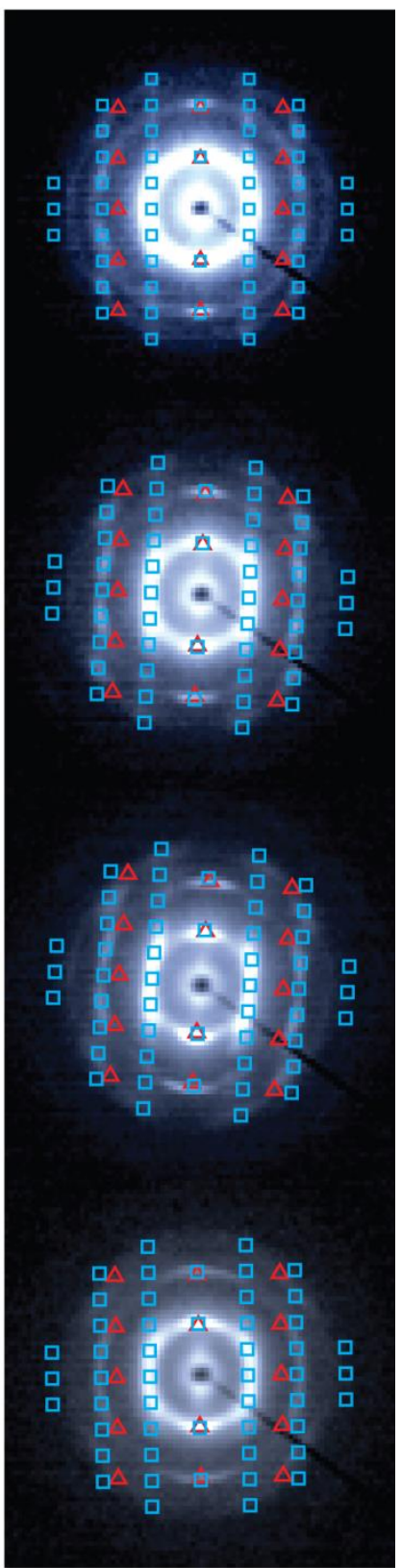

Figure S7b: Comparison of 2D SAXS data obtained in the velocity direction after LAOS at $180{ }^{\circ} \mathrm{C}$ at various local strain values, $\gamma$ (maximum strain $=100 \%$, frequency $=1 \mathrm{rad} / \mathrm{s}$ ), and patterns predicted for coexisting FCC spheres (red $\Delta$ ) and HCP spheres (blue $\square$ ). In the prediction of FCC spheres, the unit cell is aligned such that the velocity direction is parallel to the [11 $\overline{2}$ ] direction along the unit cell. In the prediction of HCP spheres, the unit cell is aligned such that the velocity direction is parallel to the $[\overline{2} 110]$ direction along the unit cell. Here in part b), the contrast is modified to improve the visibility of the higher order diffraction spots. The unit cell dimension used in the theoretical prediction was $\mathrm{a}=42 \mathrm{~nm}$ for FCC and $\mathrm{a} / \mathrm{c}=0.612, \mathrm{c}=47.2 \mathrm{~nm}$ for HCP. 


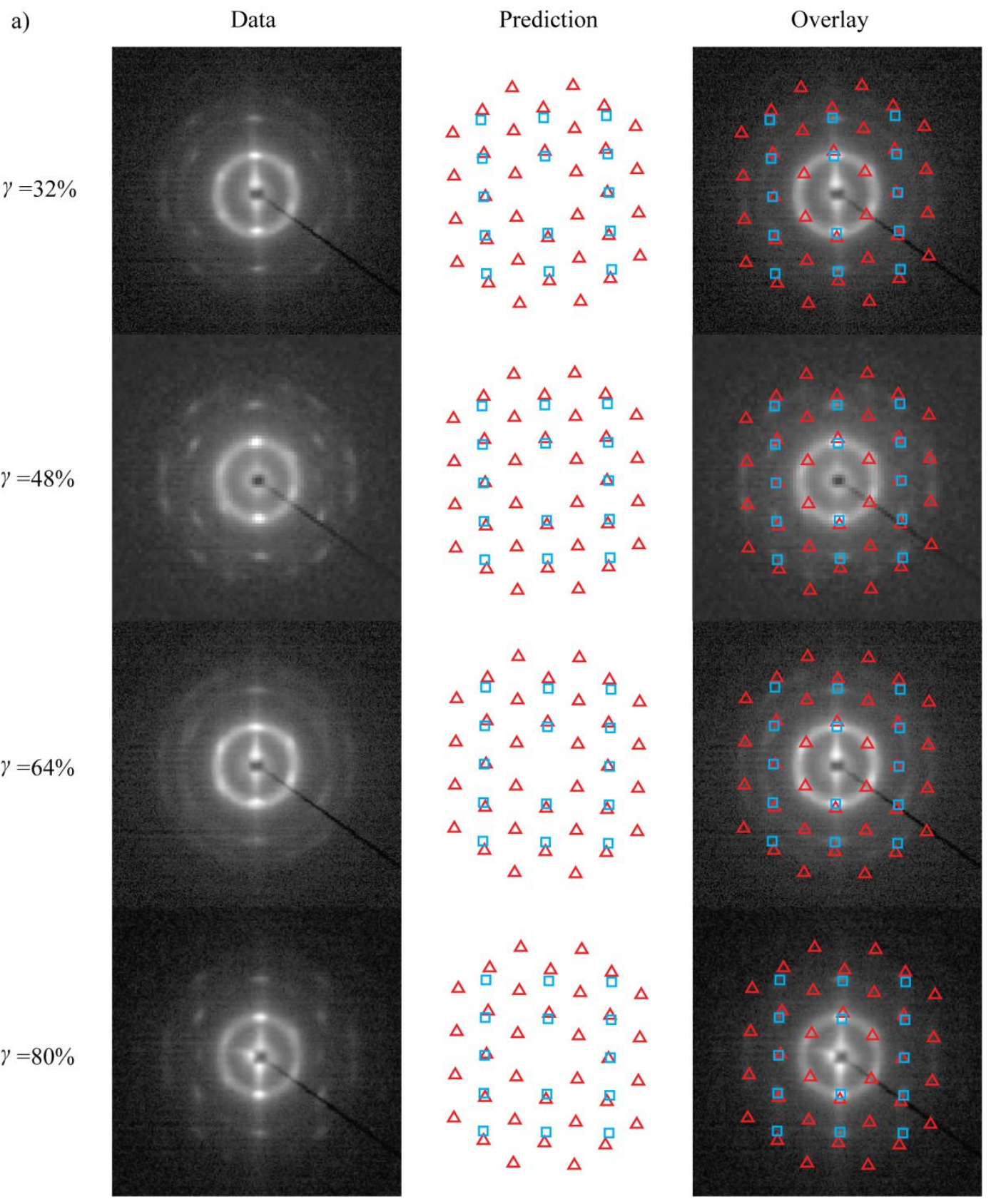

Figure S8a: Comparison of 2D SAXS data obtained in the vorticity direction after LAOS at $180{ }^{\circ} \mathrm{C}$ at various local strain values, $\gamma$ (maximum strain $=100 \%$, frequency $=1 \mathrm{rad} / \mathrm{s}$ ), and patterns predicted for coexisting FCC spheres (red $\Delta$ ) and HCP spheres (blue $\square$ ). In the prediction of FCC spheres, the unit cell is aligned such that the vorticity direction is parallel to the [1 $\overline{1} 0]$ direction along the unit cell. In the prediction of HCP spheres, the unit cell is aligned such that the vorticity direction is parallel to the [01 $\overline{1} 0]$ direction along the unit cell. The unit cell dimension used in the theoretical prediction was $\mathrm{a}=42 \mathrm{~nm}$ for $\mathrm{FCC}$ and $\mathrm{a} / \mathrm{c}=0.612, \mathrm{c}=47.2 \mathrm{~nm}$ for HCP. 
b)

Data

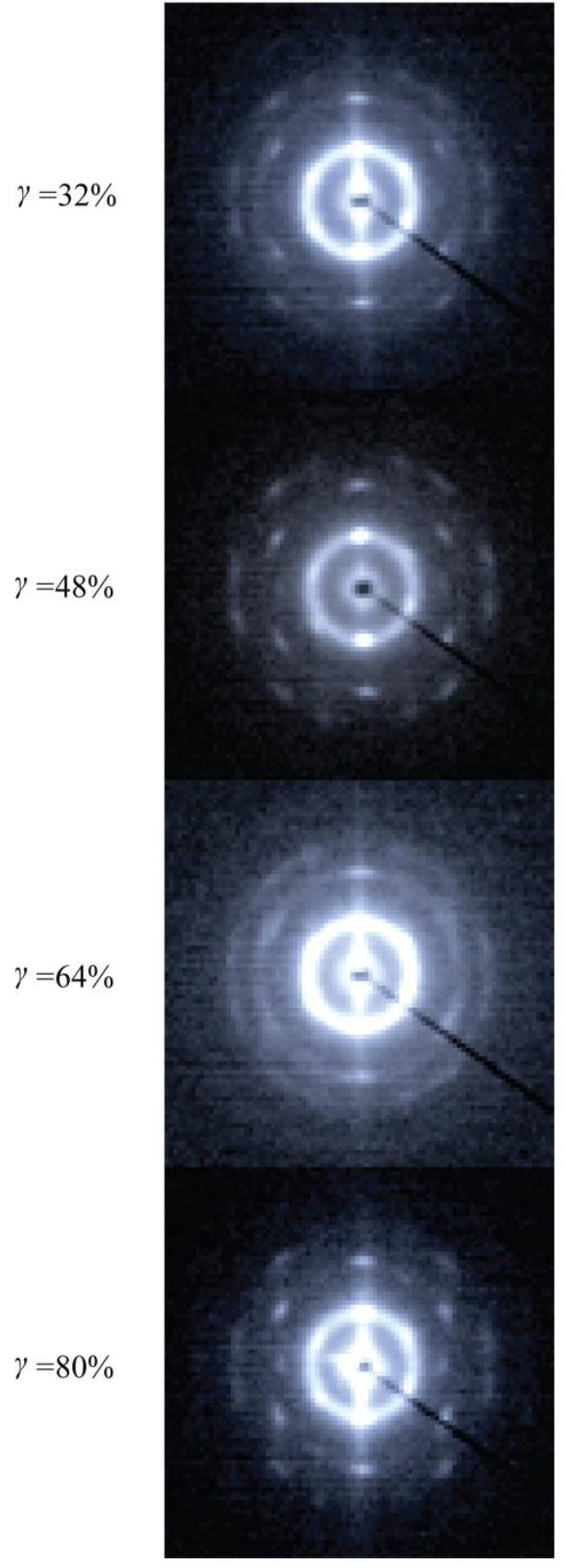

Prediction

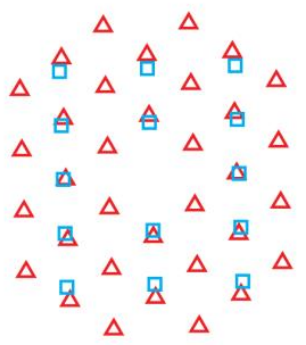

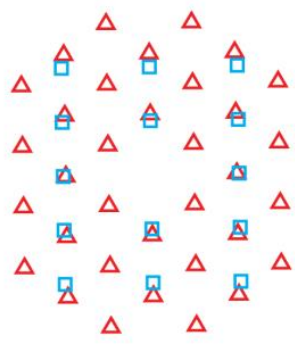

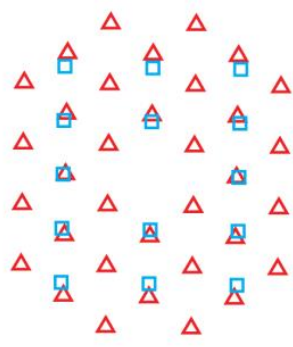

${ }_{\Delta} \stackrel{\Delta}{\Delta}_{\Delta}^{\Delta}{ }_{\Delta}^{\Delta} \Delta$ $\Delta \stackrel{\Delta}{\Delta}{ }_{\Delta}^{\Delta}{ }_{\Delta}{ }_{\Delta}$

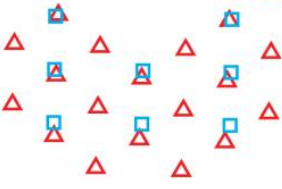

Overlay

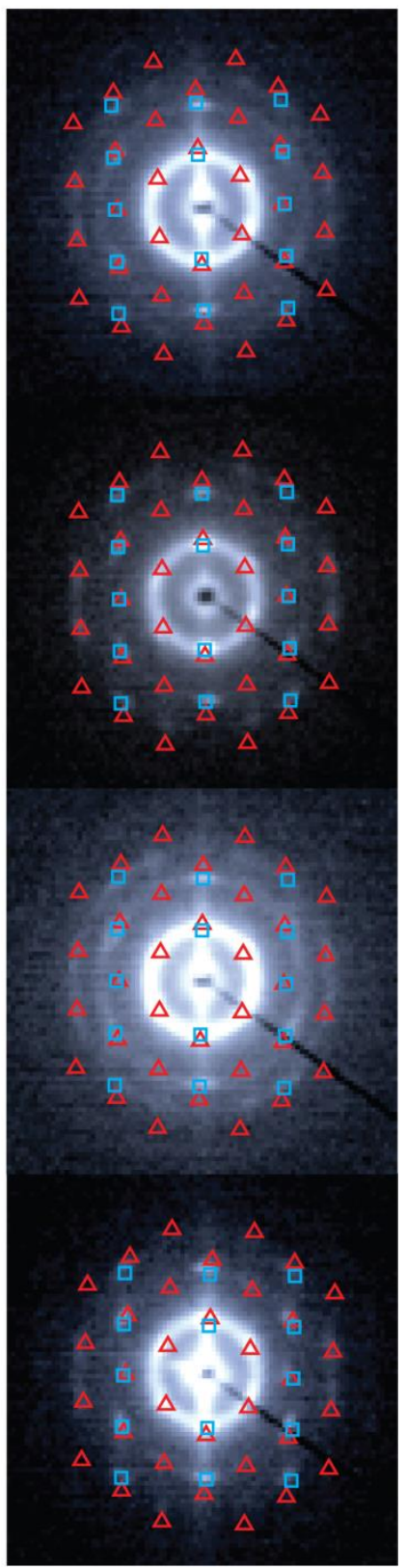

Figure S8b: Comparison of 2D SAXS data obtained in the vorticity direction after LAOS at $180{ }^{\circ} \mathrm{C}$ at various local strain values, $\gamma$ (maximum strain $=100 \%$, frequency $=1 \mathrm{rad} / \mathrm{s}$ ), and patterns predicted for coexisting FCC spheres (red $\Delta$ ) and HCP spheres (blue $\square$ ). In the prediction of FCC spheres, the unit cell is aligned such that the vorticity direction is parallel to the [1 10$]$ direction along the unit cell. In the prediction of HCP spheres, the unit cell is aligned such that the vorticity direction is parallel to the [01 $\overline{1} 0$ ] direction along the unit cell. Here in part b), the contrast is modified to improve the visibility of the higher order diffraction spots. The unit cell dimension used in the theoretical prediction was $\mathrm{a}=42 \mathrm{~nm}$ for FCC and $\mathrm{a} / \mathrm{c}=0.612, \mathrm{c}=47.2 \mathrm{~nm}$ for HCP. 


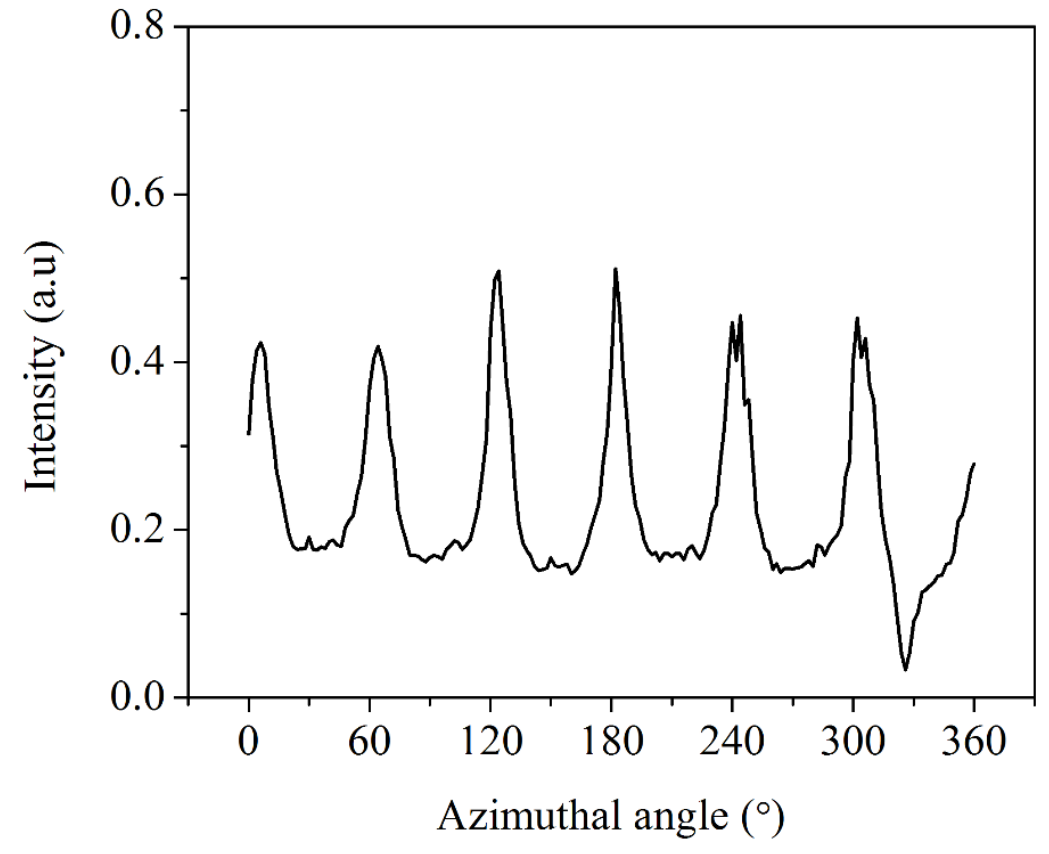

Figure S9: Representative intensity as a function of azimuthal angle of the primary scattering ring in the shear gradient direction $\left(\right.$ LAOS temperature $=180{ }^{\circ} \mathrm{C}$, local strain $=48 \%$ ). 


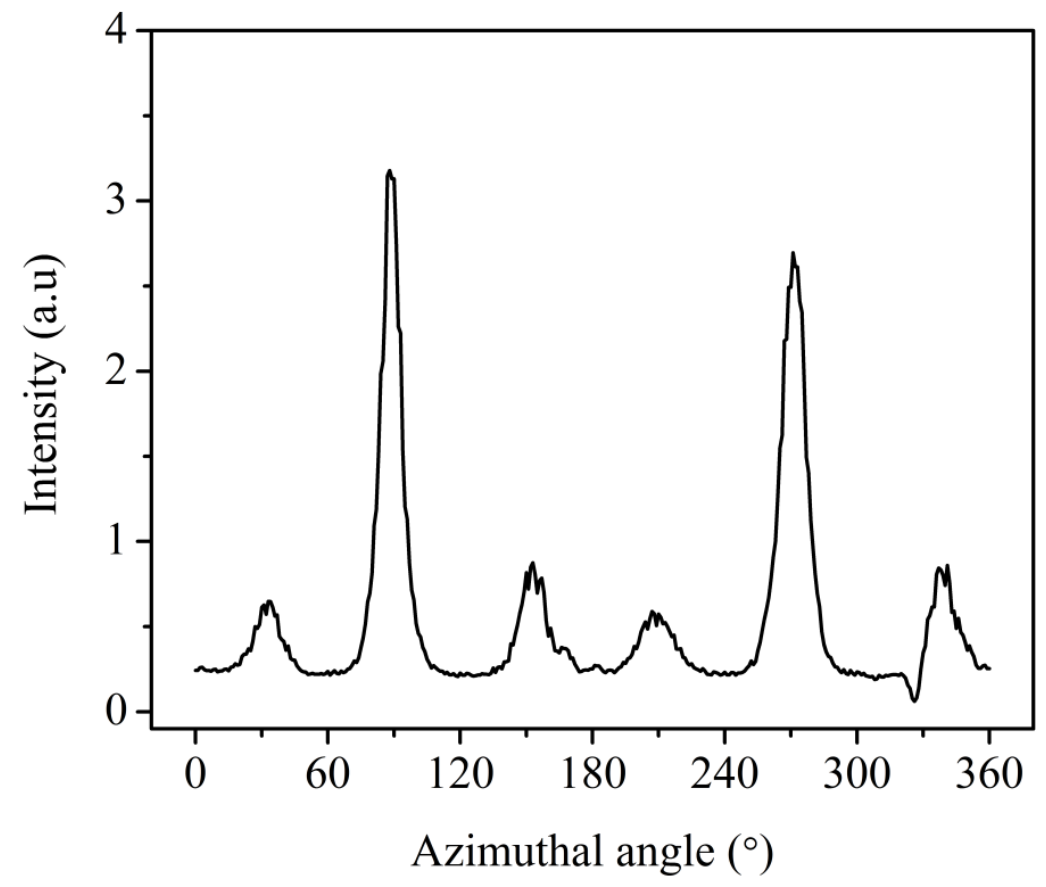

Figure S10: Representative intensity as a function of azimuthal angle of the primary scattering ring in the vorticity direction (LAOS temperature $=180^{\circ} \mathrm{C}$, local strain $=48 \%$ ). 


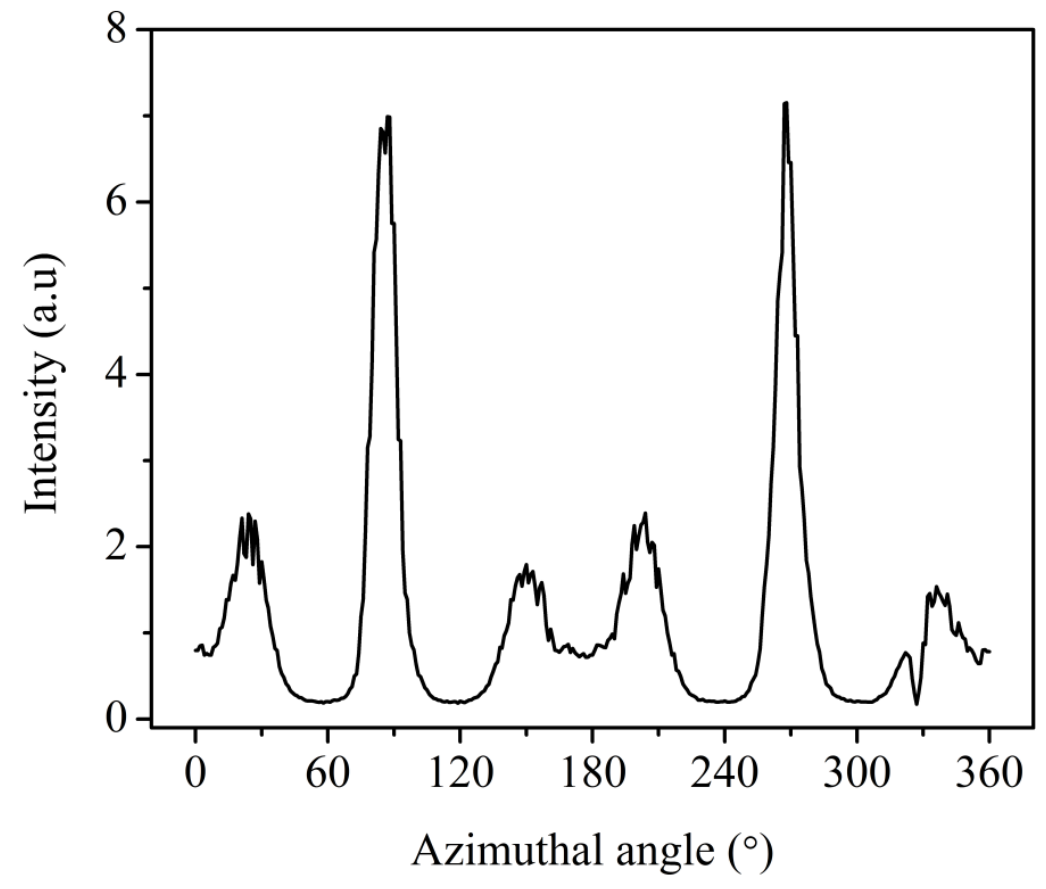

Figure S11: Representative intensity as a function of azimuthal angle of the primary scattering ring in the velocity direction (LAOS temperature $=180{ }^{\circ} \mathrm{C}$, local strain $=48 \%$ ). 


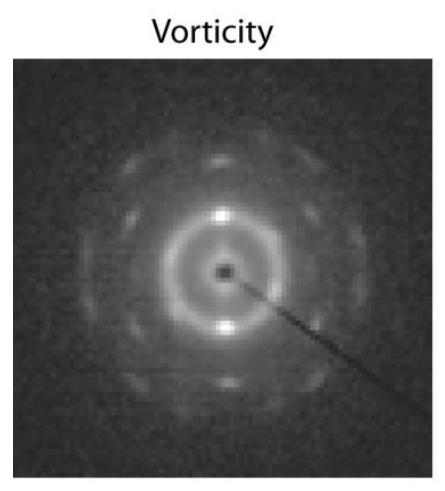

Data+FCC[11 $]$

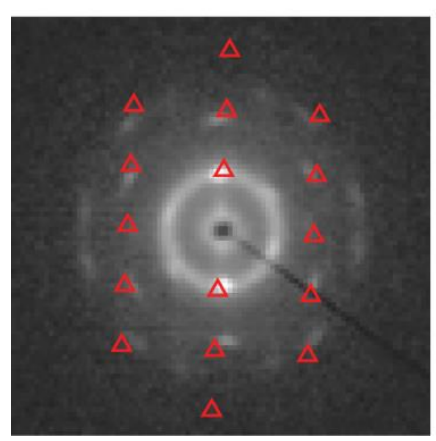

Velocity

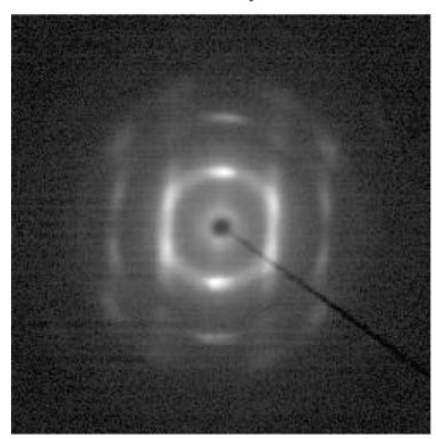

Data+FCC[1̄o]

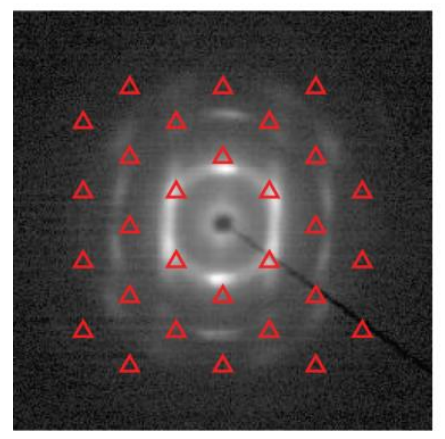

Data+HCP [0110]

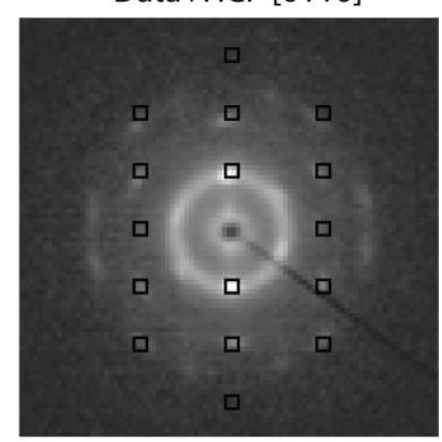

Data+HCP+FCC

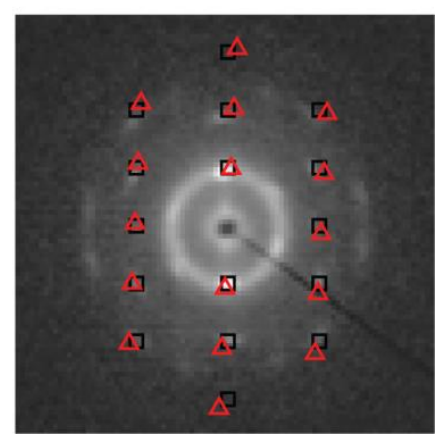

Data+HCP [2110]

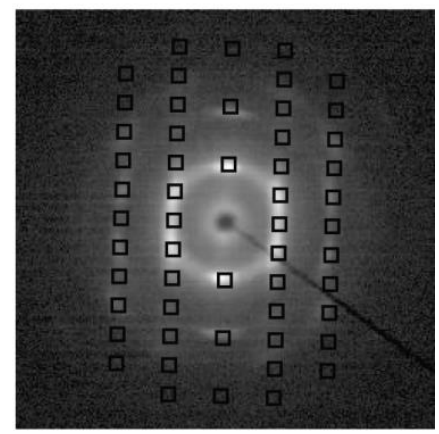

Data $+\mathrm{HCP}+\mathrm{FCC}$

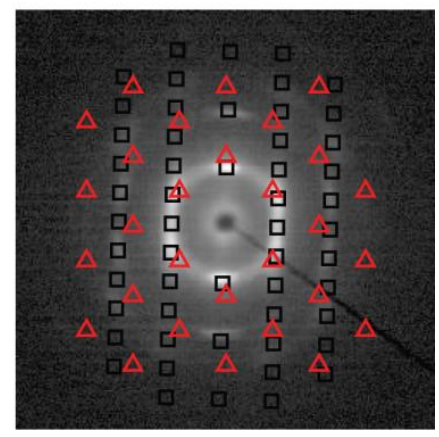

Figure S12: A comparison of the following unit cell orientations to the data (vorticity direction shown on top and velocity direction shown on bottom). For FCC, [11 $\overline{2}$ ] and [1 $\overline{1} 0]$ in the vorticity and velocity directions, respectively, and for HCP, [01 10$]$ and [ $\overline{2} 110]$ in the vorticity and velocity directions, respectively. These orientations are inconsistent with the data. 
Vorticity

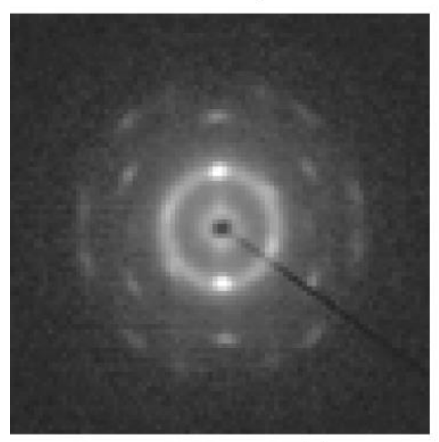

Data+FCC[112]

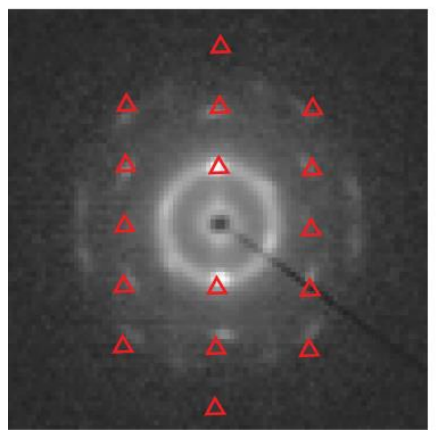

Velocity

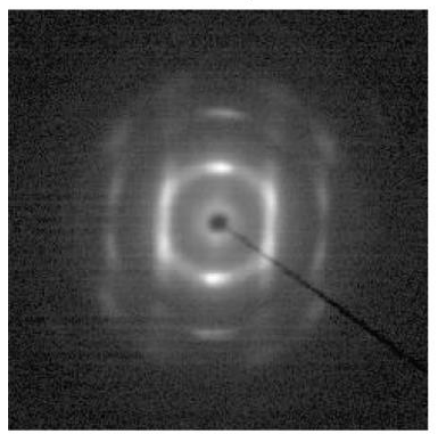

Data+FCC[1ํㅣ $]$

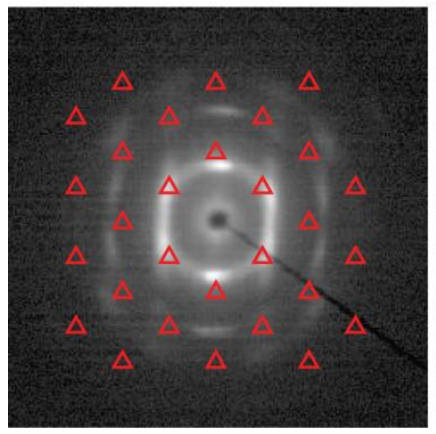

Data+HCP [2110]

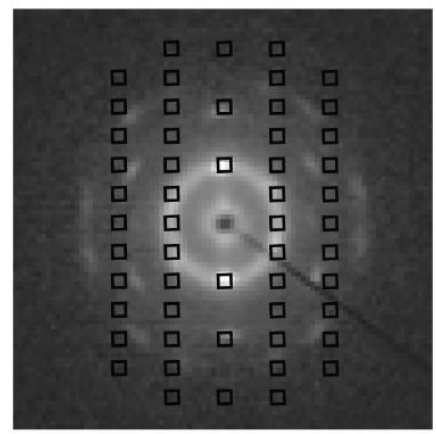

Data+HCP+FCC

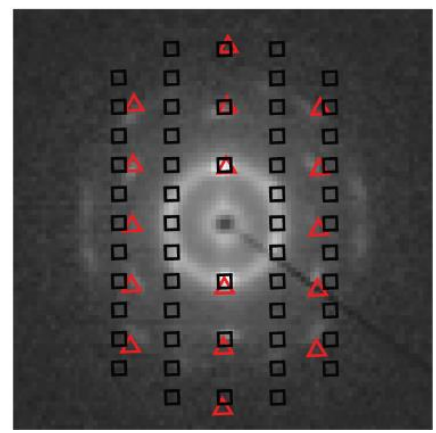

Data+HCP [01̄̄0]

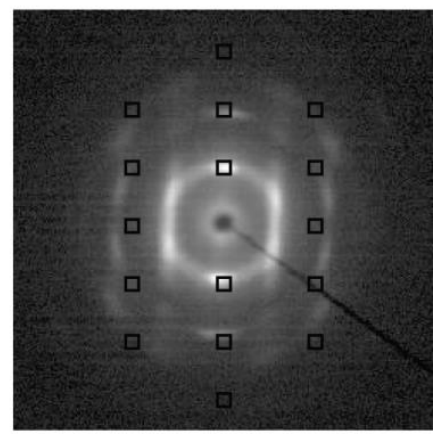

Data+HCP+FCC

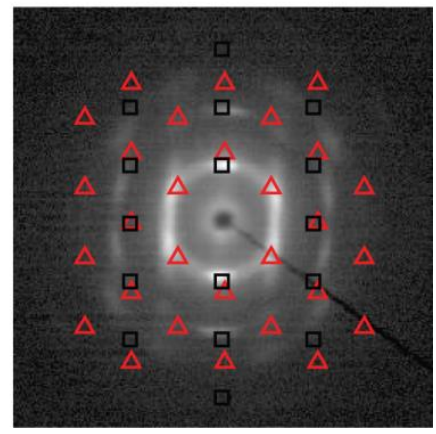

Figure S13: A comparison of the following unit cell orientations to the data (vorticity direction shown on top and velocity direction shown on bottom). For FCC, $[11 \overline{2}]$ and $[1 \overline{1} 0]$ in the vorticity and velocity directions, respectively, and for HCP, $[\overline{2} 110]$ and $[01 \overline{1} 0]$ in the vorticity and velocity directions, respectively. These orientations are inconsistent with the data. 
a)

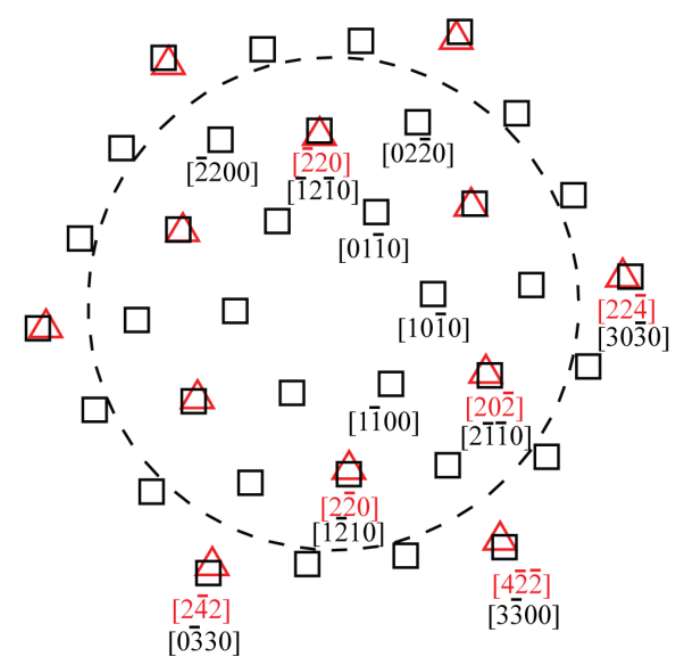

b)

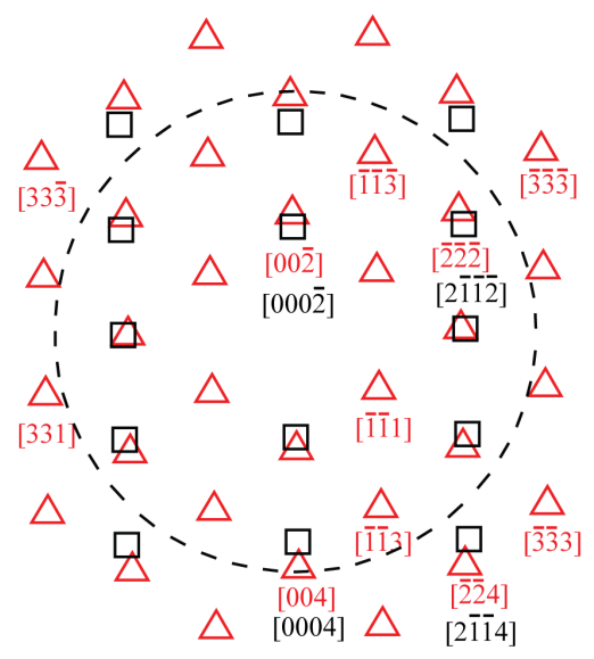

c)

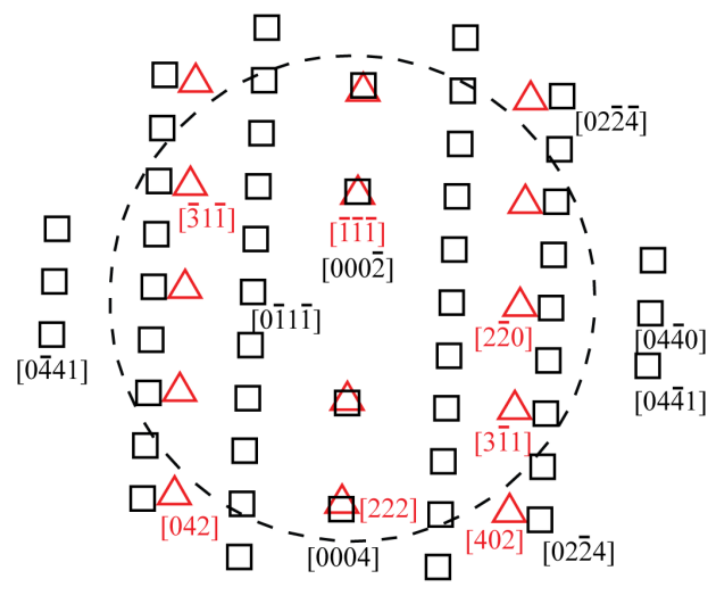

Figure S14: Indexing of the prediction for FCC (red triangle) and HCP (black square) in the a) shear gradient, b) vorticity, and c) velocity directions (LAOS temperature $=180{ }^{\circ} \mathrm{C}$, local strain $=48 \%$ ). Dotted circle indicates the prediction of the location of the first form factor minimum, using the sphere radius determined from the TEM image in Figure $8(\mathrm{r}=7.3 \mathrm{~nm})$. 


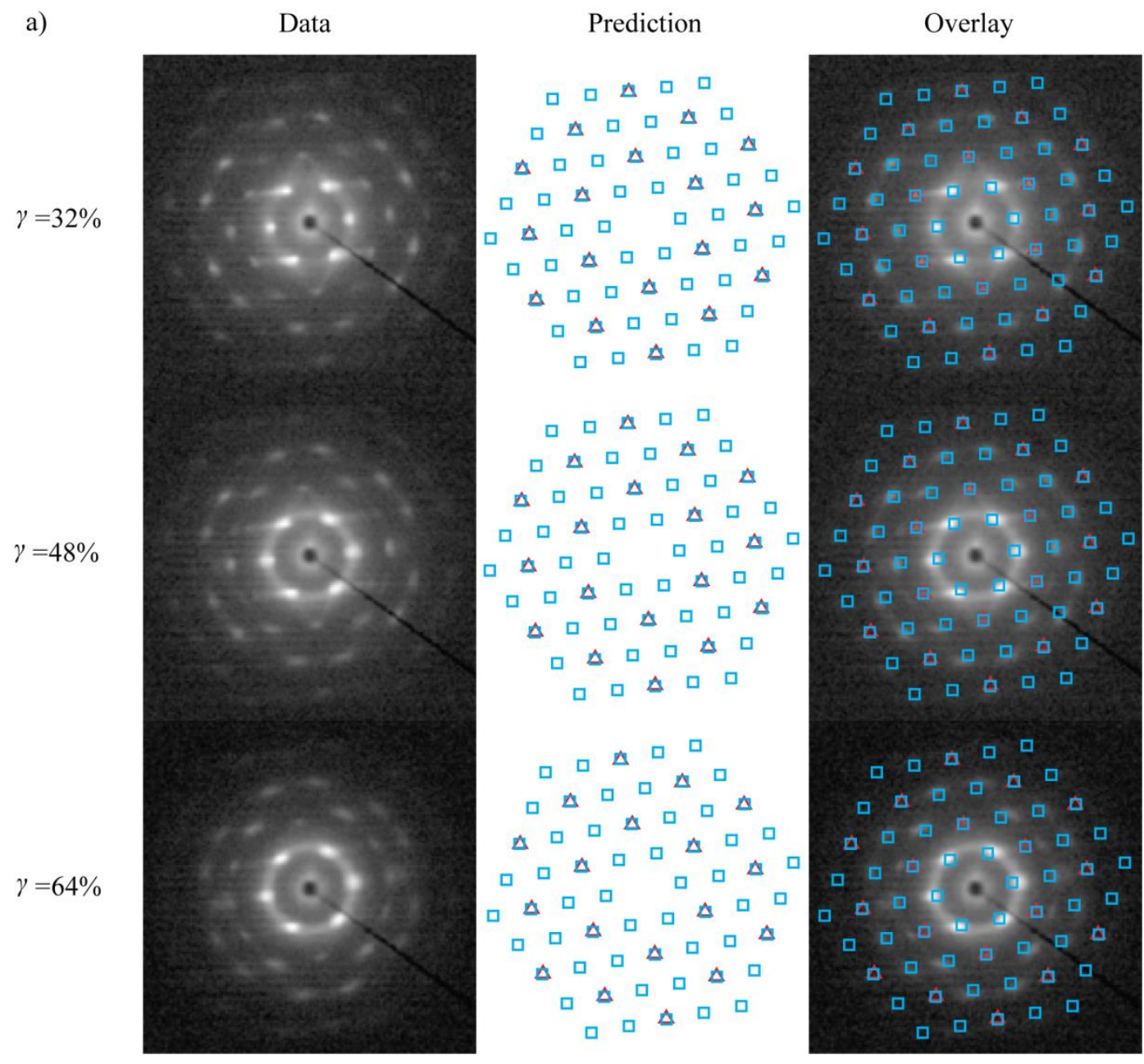

Figure S15a: Comparison of 2D SAXS data obtained in the shear gradient direction after LAOS at $130{ }^{\circ} \mathrm{C}$ at various local strain values, $\gamma$ (maximum strain $=100 \%$, frequency $=1 \mathrm{rad} / \mathrm{s}$ ), and patterns predicted for coexisting FCC spheres (red $\Delta$ ) and HCP spheres (blue $\square$ ). In the prediction of FCC spheres, the unit cell is aligned such that the shear gradient direction is parallel to the [111] direction along the unit cell. In the prediction of HCP spheres, the unit cell is aligned such that the shear gradient direction is parallel to the [0001] direction along the unit cell. The unit cell dimension used in the theoretical prediction was $\mathrm{a}=45 \mathrm{~nm}$ for FCC and $\mathrm{a} / \mathrm{c}=0.62, \mathrm{c}=51 \mathrm{~nm}$ for HCP. 
b)

Data

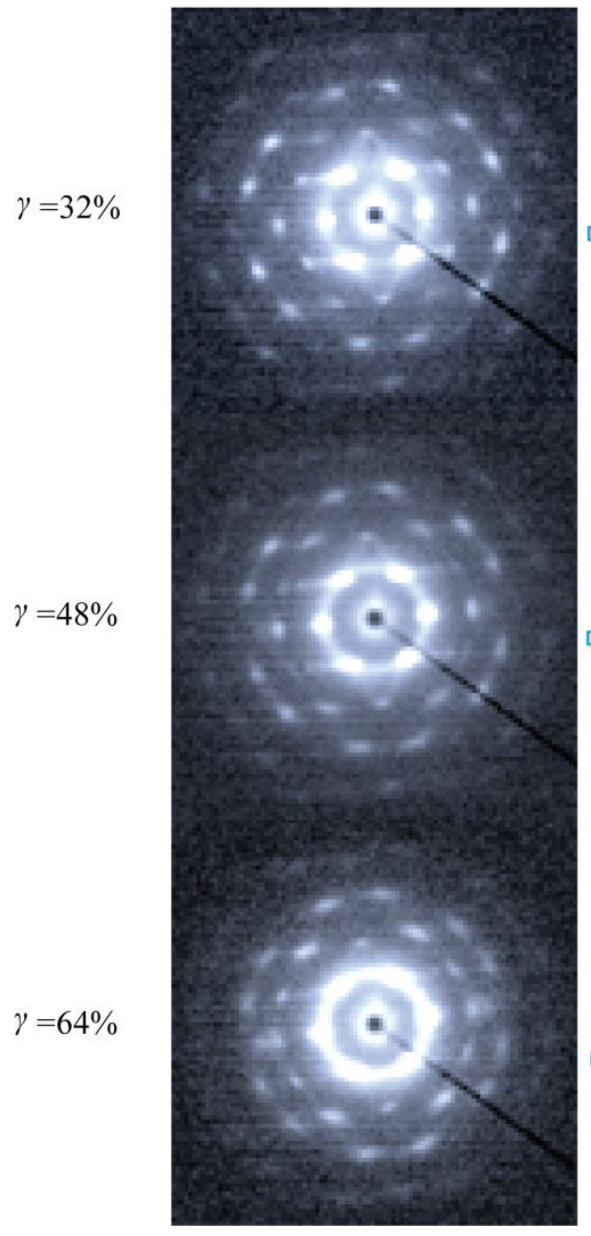

Prediction

ㅁ $\triangle \square \square$

$\triangle \Delta \square \square \Delta$

$\triangle \square \square \Delta \square \square \Delta$

ㅁ $\Delta \square \square \Delta \square \square$

$\triangle \square \square \square \square \Delta \square$

$\square \triangle \square \square \Delta \square \square$

$\Delta \square \square \Delta \square \square \Delta$

$\Delta \square \square \Delta \square$

$\square \square \Delta \square \square$

ㅁ $\triangle \square \square$

$\square \Delta \square \square \Delta \square$

$\triangle \square \square \Delta \square \Delta$

$\triangle \square \square \square$

$\square \square \Delta \square$

$\triangle \square \square \Delta \square \square$

$\Delta \square \square \Delta \square \square \Delta$

ㅁ $\Delta$ ㅁ $\Delta$ 口

ㅁ $\Delta \square \square$

ㅁ $\Delta$ ㅁ $\square$

$\Delta \square \square \Delta \square$

$\triangle \square \square \Delta \square$

$\square \Delta \square \square \Delta \square$

$\triangle \square \square \square \Delta \square$

$\square \square \Delta \square \Delta \square \square$

$\Delta \square \Delta \square \Delta \square$

$\square \Delta \Delta \square \square$

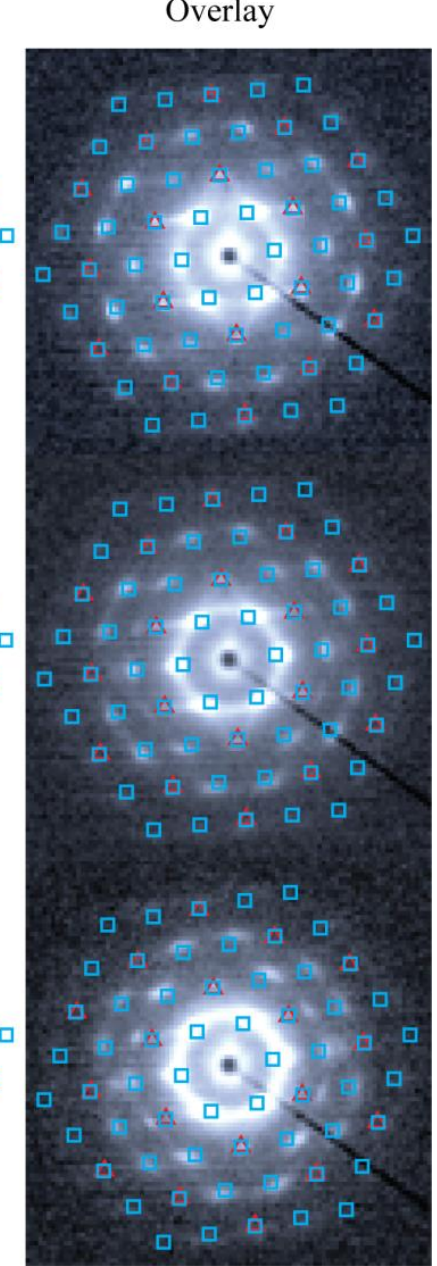

Figure S15b: Comparison of 2D SAXS data obtained in the shear gradient direction after LAOS at $130{ }^{\circ} \mathrm{C}$ at various local strain values, $\gamma$ (maximum strain $=100 \%$, frequency $=1 \mathrm{rad} / \mathrm{s}$ ), and patterns predicted for coexisting FCC spheres (red $\Delta$ ) and HCP spheres (blue $\square$ ). In the prediction of FCC spheres, the unit cell is aligned such that the shear gradient direction is parallel to the [111] direction along the unit cell. In the prediction of HCP spheres, the unit cell is aligned such that the shear gradient direction is parallel to the [0001] direction along the unit cell. Here in part b), the contrast is modified to improve the visibility of the higher order diffraction spots. The unit cell dimension used in the theoretical prediction was $\mathrm{a}=45 \mathrm{~nm}$ for $\mathrm{FCC}$ and $\mathrm{a} / \mathrm{c}=0.62, \mathrm{c}=51 \mathrm{~nm}$ for HCP. 


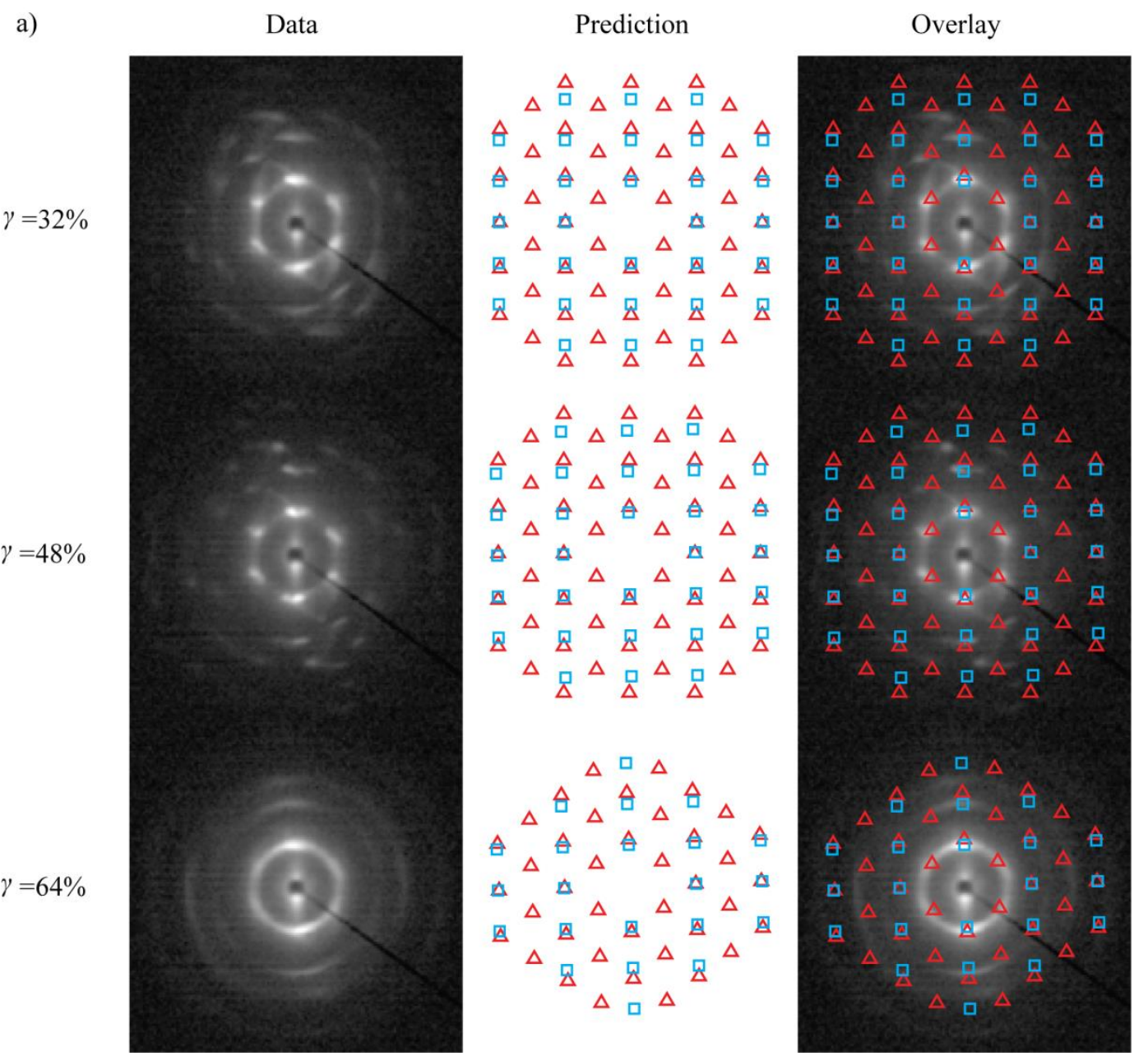

Figure S16a: Comparison of 2D SAXS data obtained in the vorticity direction after LAOS at $130{ }^{\circ} \mathrm{C}$ at various local strain values, $\gamma$ (maximum strain $=100 \%$, frequency $=1 \mathrm{rad} / \mathrm{s}$ ), and patterns predicted for coexisting FCC spheres (red $\Delta$ ) and HCP spheres (blue $\square$ ). In the prediction of FCC spheres, the unit cell is aligned such that the velocity direction is parallel to the [1̄ㅣ] direction along the unit cell. In the prediction of HCP spheres, the unit cell is aligned such that the velocity direction is parallel to the [01 $\overline{1} 0]$ direction along the unit cell. The unit cell dimension used in the theoretical prediction was $\mathrm{a}=45 \mathrm{~nm}$ for $\mathrm{FCC}$ and $\mathrm{a} / \mathrm{c}=0.62, \mathrm{c}=51 \mathrm{~nm}$ for HCP. 


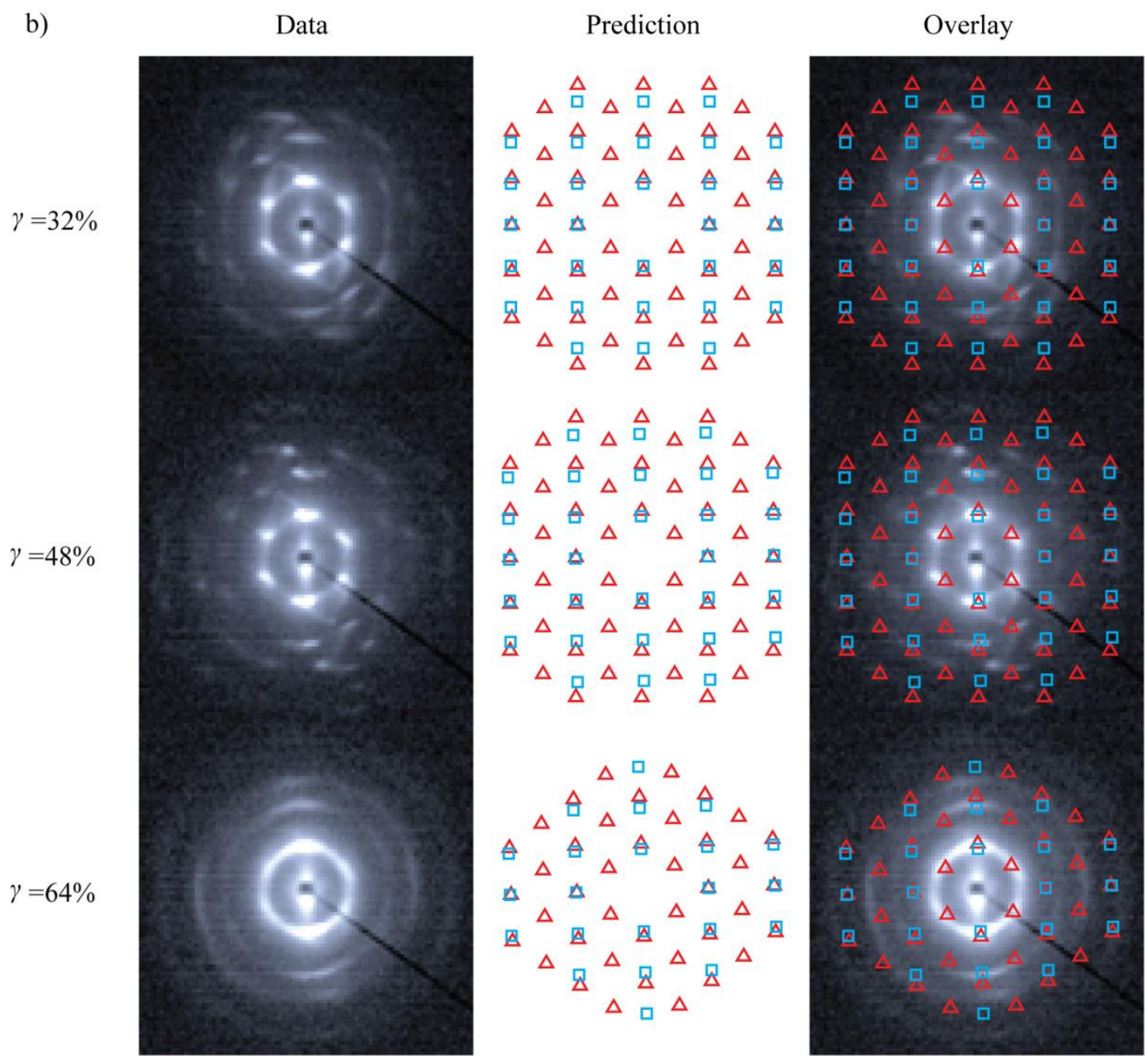

Figure S16b: Comparison of 2D SAXS data obtained in the vorticity direction after LAOS at $130{ }^{\circ} \mathrm{C}$ at various local strain values, $\gamma$ (maximum strain $=100 \%$, frequency $=1 \mathrm{rad} / \mathrm{s}$ ), and patterns predicted for coexisting FCC spheres (red $\Delta$ ) and HCP spheres (blue $\square$ ). In the prediction of FCC spheres, the unit cell is aligned such that the velocity direction is parallel to the [1 $\overline{1} 0]$ direction along the unit cell. In the prediction of HCP spheres, the unit cell is aligned such that the velocity direction is parallel to the [01 10 ] direction along the unit cell. Here in part b), the contrast is modified to improve the visibility of the higher order diffraction spots. The unit cell dimension used in the theoretical prediction was $\mathrm{a}=45 \mathrm{~nm}$ for $\mathrm{FCC}$ and $\mathrm{a} / \mathrm{c}=0.62, \mathrm{c}=51 \mathrm{~nm}$ for HCP. 


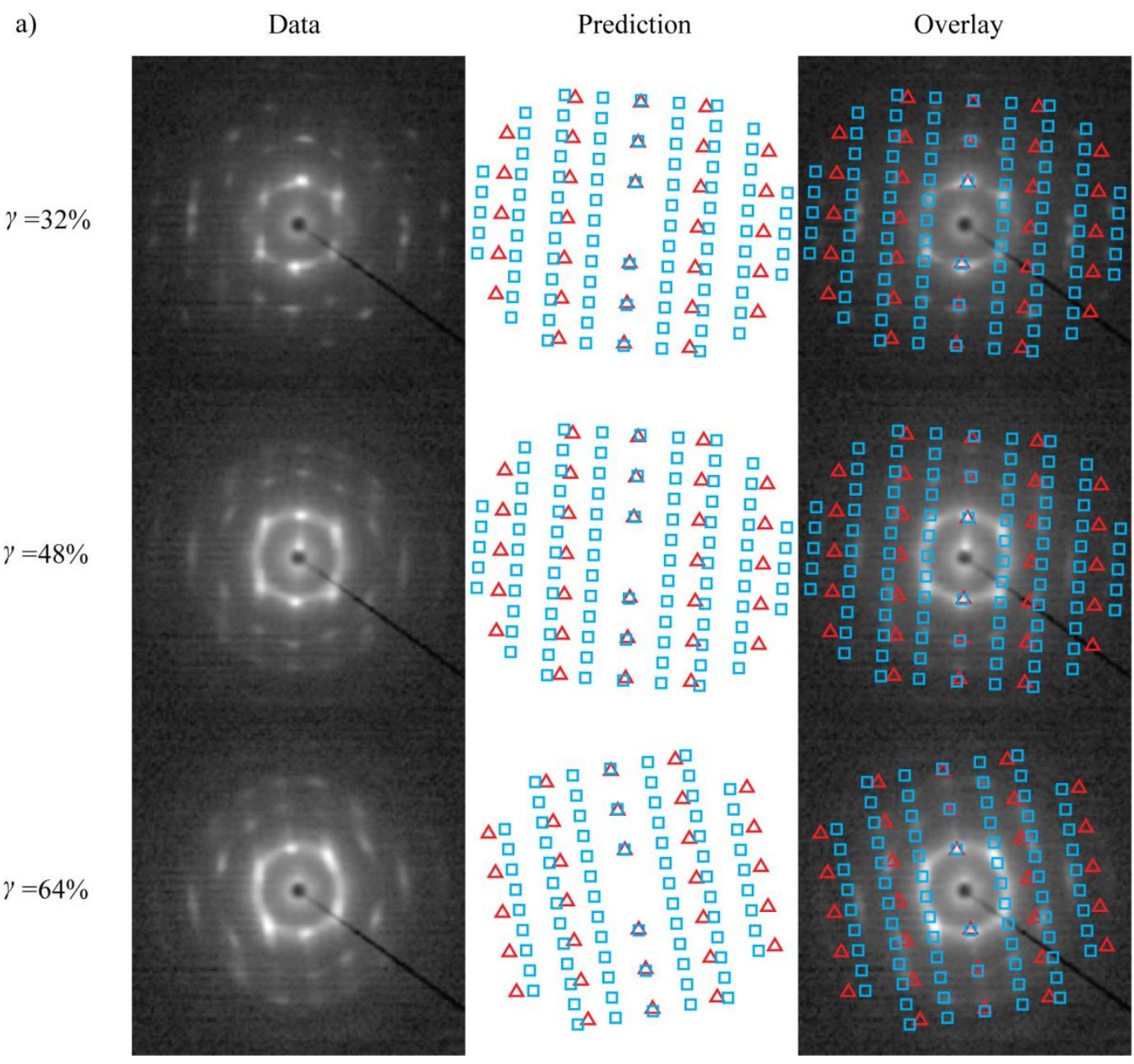

Figure S17a: Comparison of 2D SAXS data obtained in the velocity direction after LAOS at $130{ }^{\circ} \mathrm{C}$ at various local strain values, $\gamma$ (maximum strain $=100 \%$, frequency $=1 \mathrm{rad} / \mathrm{s}$ ), and patterns predicted for coexisting FCC spheres (red $\Delta$ ) and HCP spheres (blue $\square$ ). In the prediction of FCC spheres, the unit cell is aligned such that the vorticity direction is parallel to the [11 $\overline{2}$ ] direction along the unit cell. In the prediction of HCP spheres, the unit cell is aligned such that the vorticity direction is parallel to the $[\overline{2} 110]$ direction along the unit cell. The unit cell dimension used in the theoretical prediction was $\mathrm{a}=45 \mathrm{~nm}$ for FCC and $\mathrm{a} / \mathrm{c}=0.62, \mathrm{c}=51 \mathrm{~nm}$ for HCP. 
b)

Data

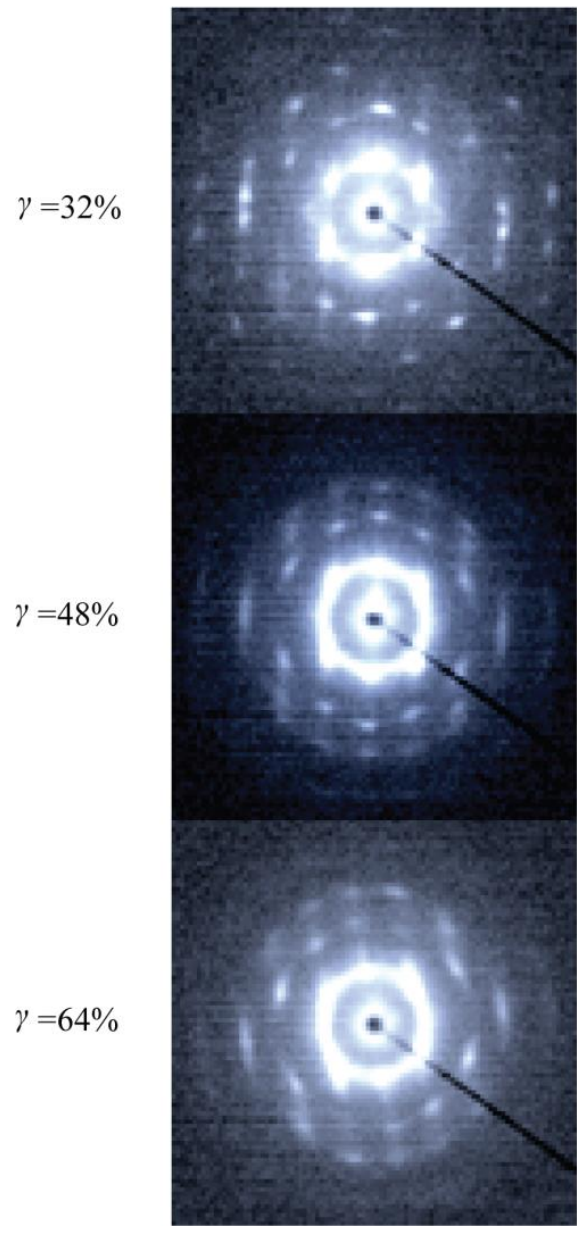

Prediction

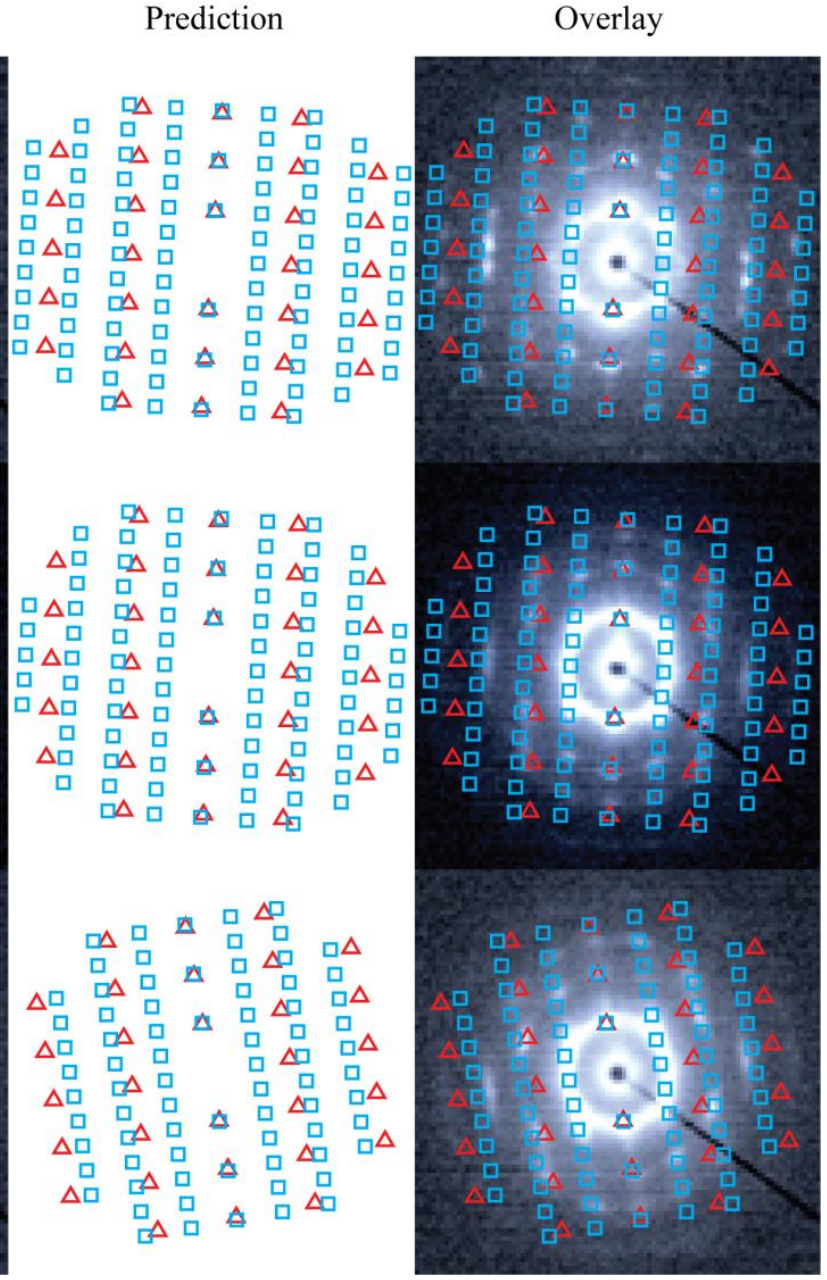

Figure S17b: Comparison of 2D SAXS data obtained in the velocity direction after LAOS at $130{ }^{\circ} \mathrm{C}$ at various local strain values, $\gamma$ (maximum strain $=100 \%$, frequency $=1 \mathrm{rad} / \mathrm{s}$ ), and patterns predicted for coexisting FCC spheres (red $\Delta$ ) and HCP spheres (blue $\square$ ). In the prediction of FCC spheres, the unit cell is aligned such that the vorticity direction is parallel to the [11 $\overline{2}]$ direction along the unit cell. In the prediction of HCP spheres, the unit cell is aligned such that the vorticity direction is parallel to the [ $\overline{2} 110]$ direction along the unit cell. Here in part $b$ ), the contrast is modified to improve the visibility of the higher order diffraction spots. The unit cell dimension used in the theoretical prediction was $\mathrm{a}=45 \mathrm{~nm}$ for FCC and $\mathrm{a} / \mathrm{c}=0.62, \mathrm{c}=51 \mathrm{~nm}$ for HCP. 


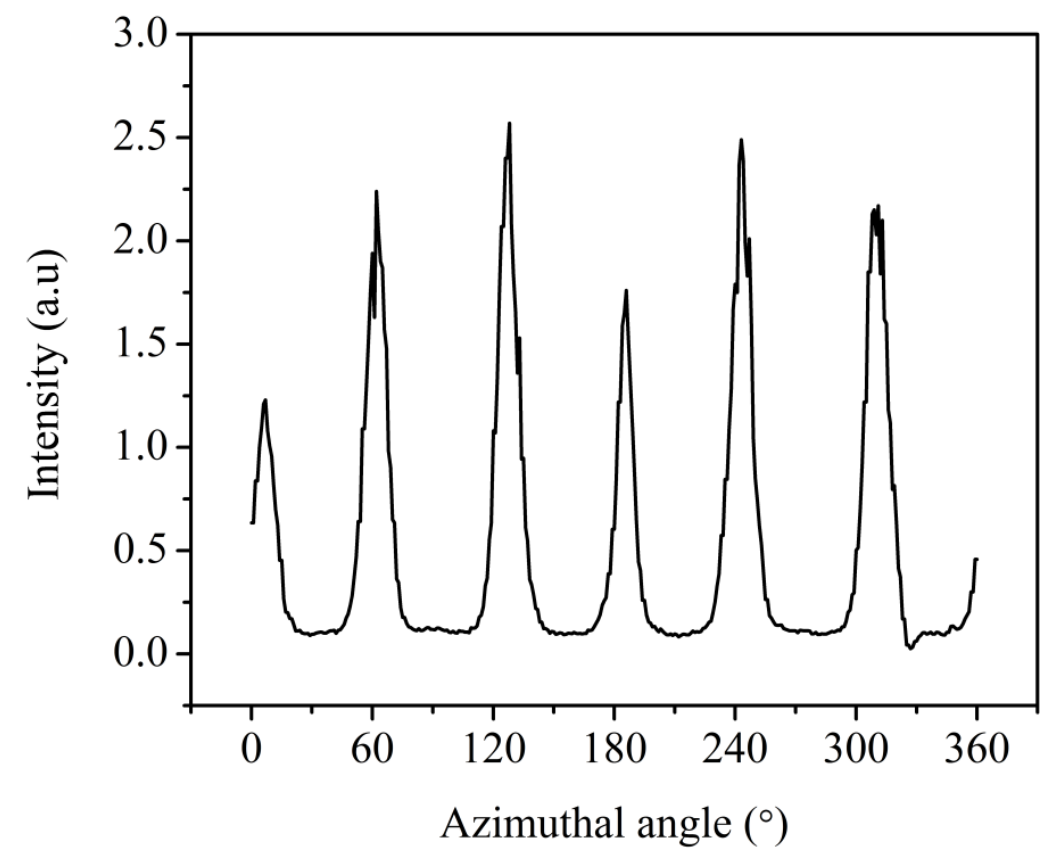

Figure S18: Representative intensity as a function of azimuthal angle of the primary scattering ring in the velocity gradient direction (LAOS temperature $=130{ }^{\circ} \mathrm{C}$, local strain $=48 \%$ ). 


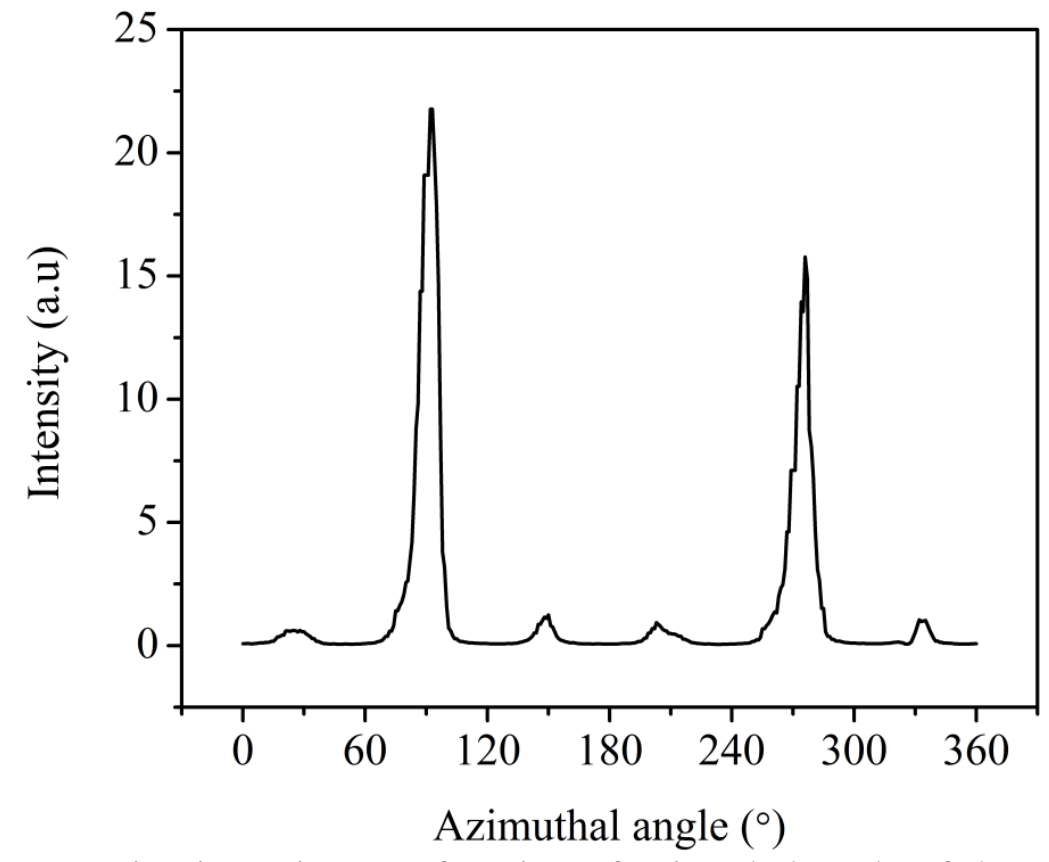

Figure S19: Representative intensity as a function of azimuthal angle of the primary scattering ring in the vorticity direction (LAOS temperature $=130{ }^{\circ} \mathrm{C}$, local strain $=48 \%$ ). 


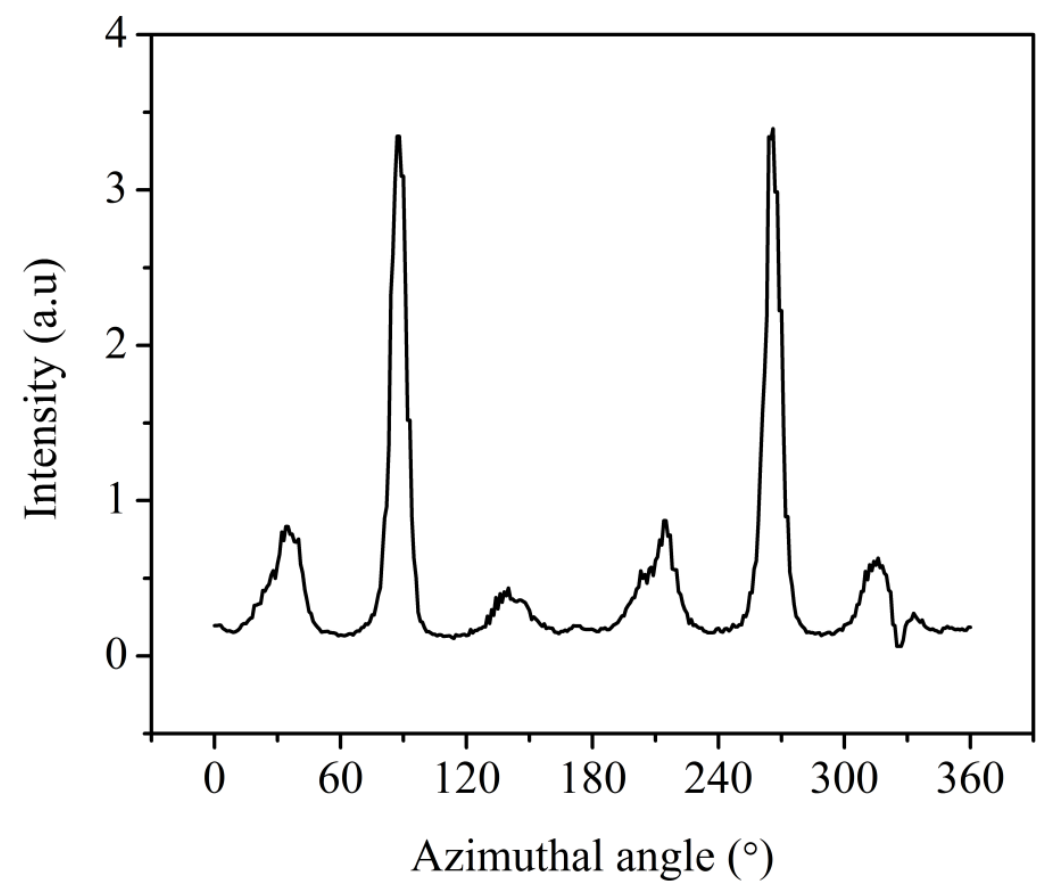

Figure S20: Representative intensity as a function of azimuthal angle of the primary scattering ring in the velocity direction (LAOS temperature $=130{ }^{\circ} \mathrm{C}$, local strain $=48 \%$ ). 
a)

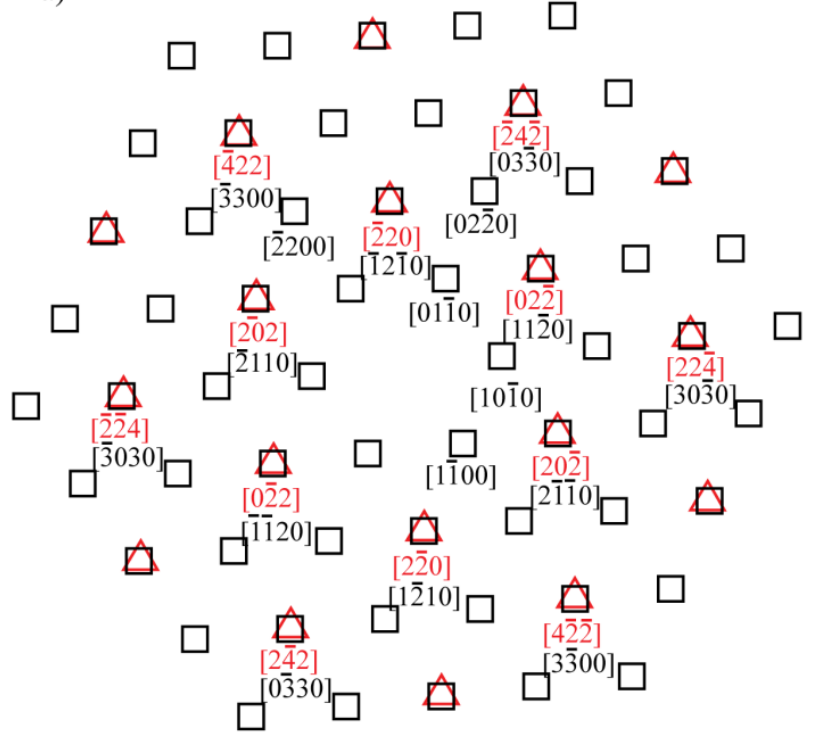

c)

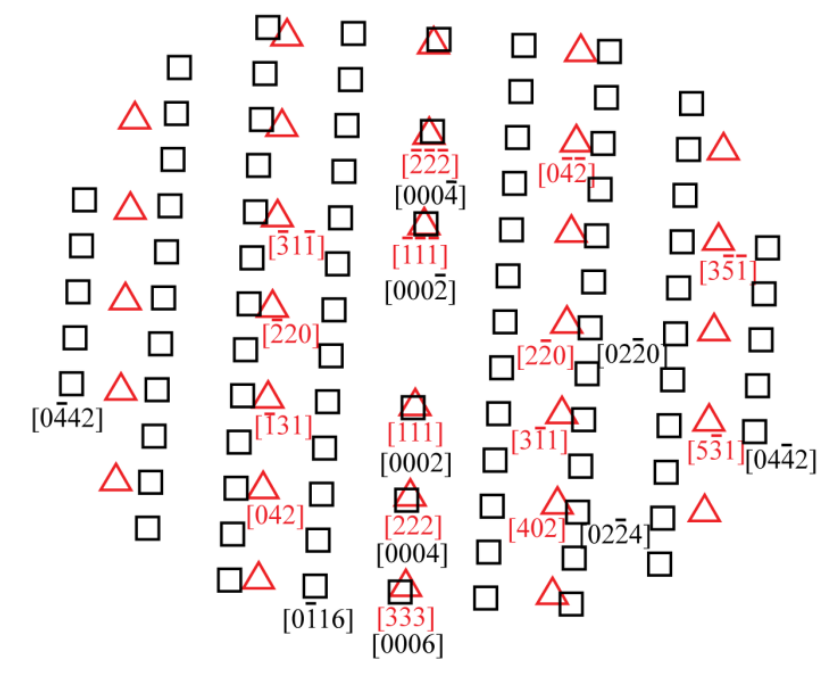

b)

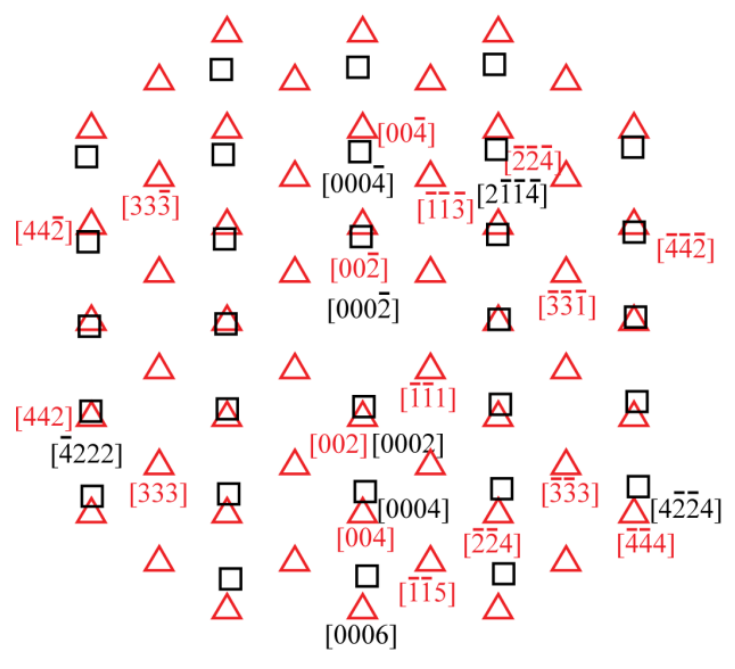

Figure S21: Indexing of the prediction for FCC (red triangle) and HCP (black square) in the a) shear gradient, b) vorticity, and c) velocity directions (LAOS temperature $=130^{\circ} \mathrm{C}$, local strain $=48 \%$ ). 
Data

a) Shear gradient direction

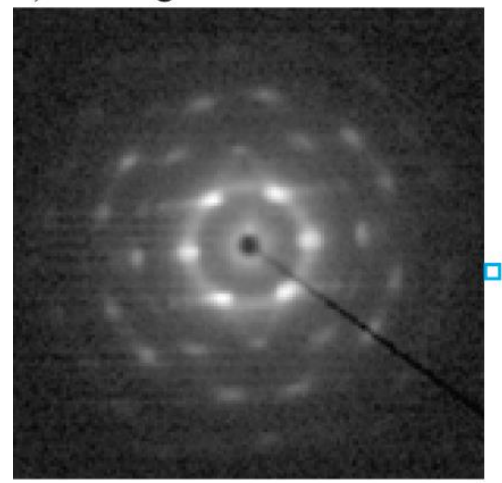

b) Vorticity direction

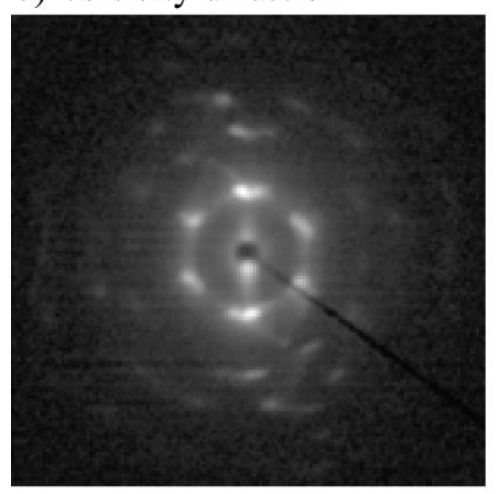

c) Velocity direction

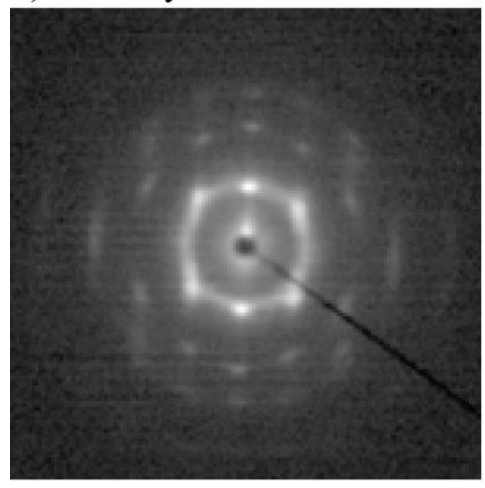

Prediction

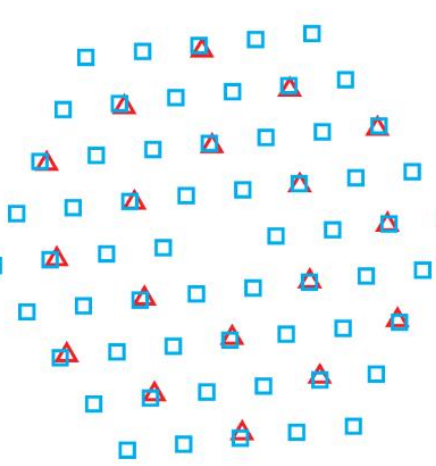

Overlay

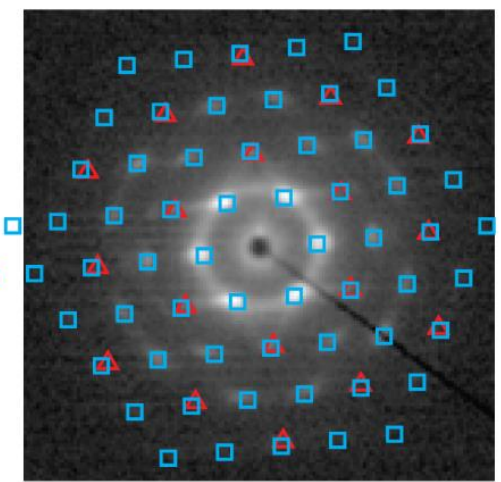

FCC:

$\mathrm{a}=435$

HCP:

$\mathrm{a} / \mathrm{c}=0.612$

$c=490$
FCC:

$\mathrm{a}=450$

HCP:

$\mathrm{a} / \mathrm{c}=0.612$

$\mathrm{c}=480$

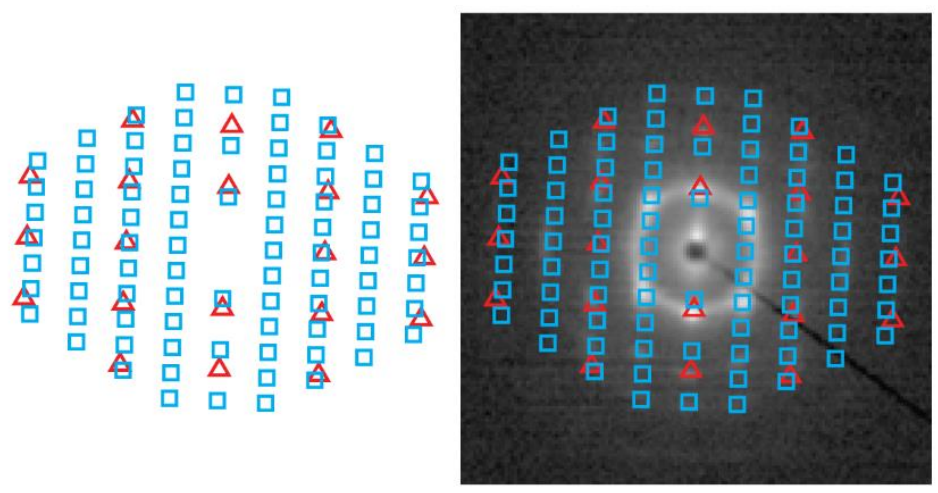

FCC:

$\mathrm{a}=420$

HCP:

$\mathrm{a} / \mathrm{c}=0.612$

$\mathrm{C}=580$

Figure S22: Comparison of 2D SAXS data obtained in the a) shear gradient, b) vorticity, and c) velocity directions after LAOS at $130{ }^{\circ} \mathrm{C}$ at local strain $\gamma=48 \%$ (maximum strain $=100 \%$, frequency $=1 \mathrm{rad} / \mathrm{s}$ ), and patterns predicted for coexisting FCC spheres (red $\Delta$ ) and HCP spheres (blue $\square$ ). The unit cells are oriented as discussed in the captions to Figures S15-S17. Here, the unit cell dimensions are allowed to vary for each shear direction (they are constrained in Figure S15$\mathrm{S} 17$ to be equal for all three shear directions). 

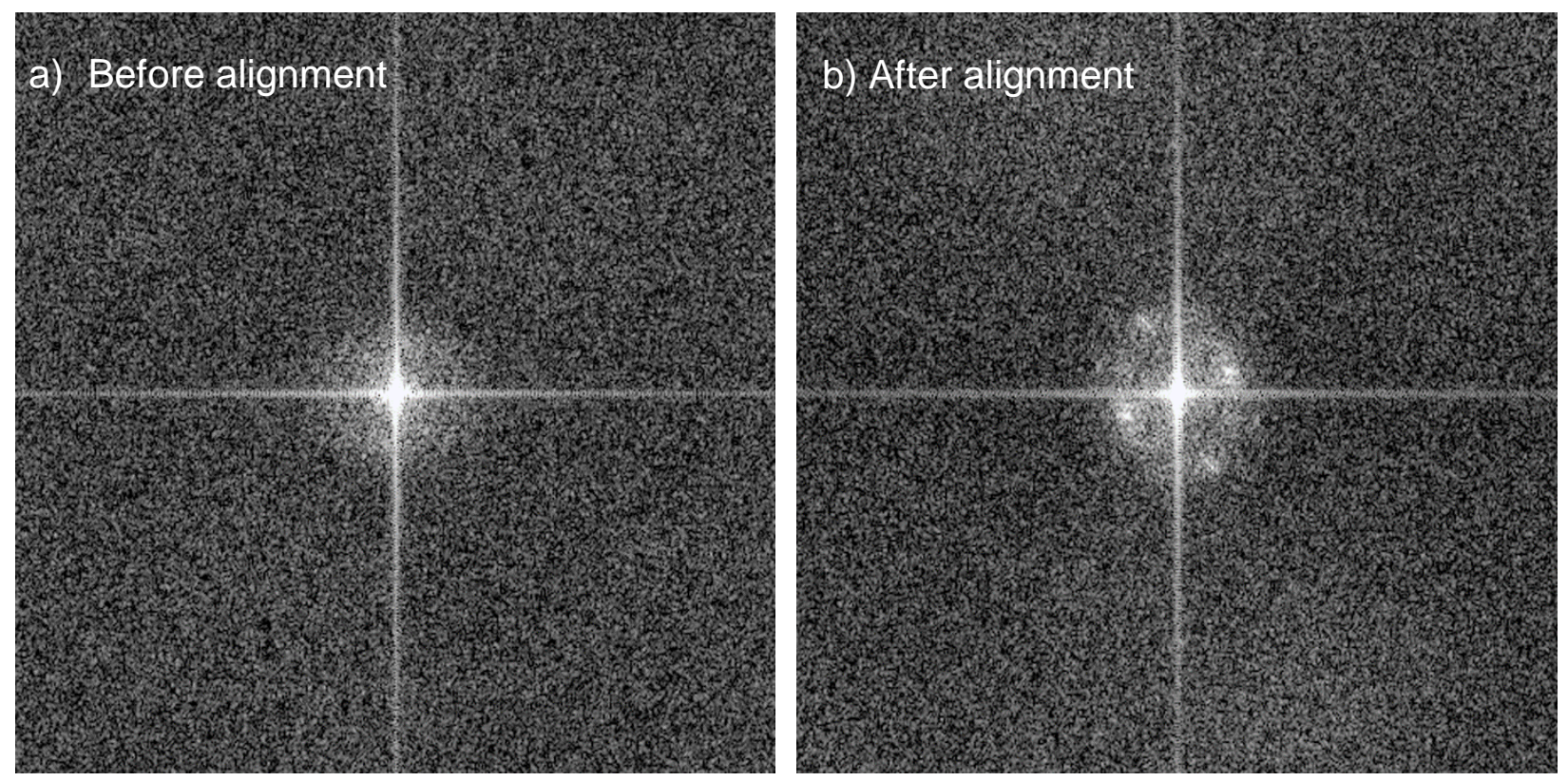

Figure S23: Fast Fourier Transforms (FFTs) of TEM micrographs obtained from the SAS triblock copolymer a) prior to alignment (TEM micrograph is shown in Figure $2 b$ of the main text) and $b$ ) following alignment with LAOS at $180{ }^{\circ} \mathrm{C}$ and $1 \mathrm{rad} / \mathrm{s}$ (TEM micrograph is shown in Figure 8 of the main text). 

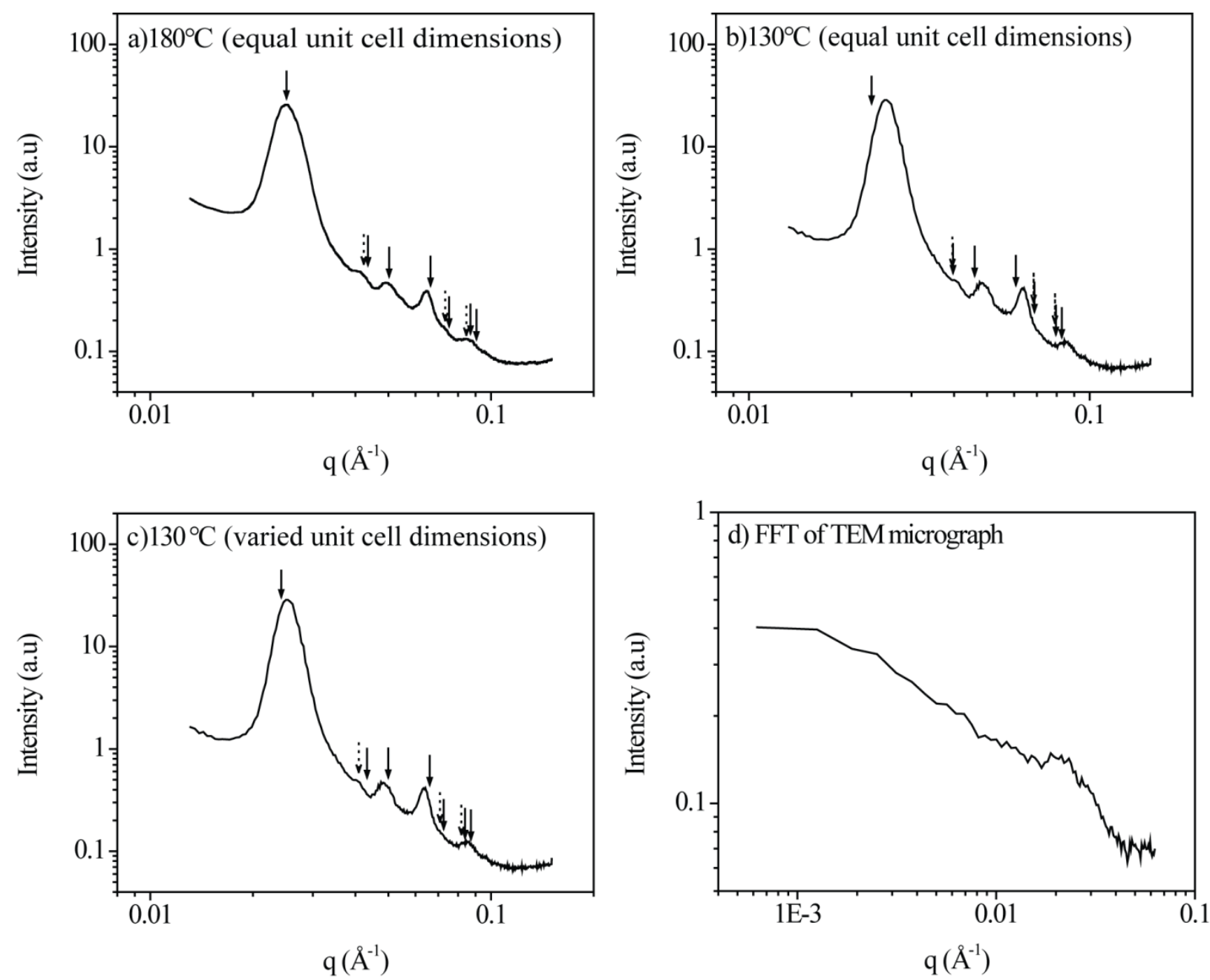

Figure S24: 1D SAXS profiles obtained from the SAS triblock copolymer following LAOS at a) $180{ }^{\circ} \mathrm{C}$, b) $130{ }^{\circ} \mathrm{C}$ (with equal unit cell dimensions in all shear directions), and c) $130{ }^{\circ} \mathrm{C}$ (with unit cell dimensions which were allowed to vary in the three shear directions). 2D SAXS data obtained in the shear gradient direction (at a local strain of 48\%) shown in the main text (Figures 5 and 7) were azimuthally averaged to create these plots. The FCC and HCP unit cell dimensions (provided in the captions to Figures 5 and 7) were used to determine the location of the primary peak position. The arrows show the expected locations for the higher order peaks expected for HCP (solid arrows) and FCC (dashed arrows) spherical structures. d) 1D profile obtained from the FFT of the TEM micrograph of the aligned sample shown in Figure S22.

In a): the primary peak is located at $q=0.0251 \AA^{-1}$ for HCP and $0.0423 \AA^{-1}$ for FCC. In b): the primary peak is located at $q=0.0229 \AA^{-1}$ for HCP and $0.0395 \AA^{-1}$ for FCC. In c): the primary peak is located at $q=0.0242 \AA^{-1}$ for HCP and $0.0409 \AA^{-1}$ for FCC. For FCC spheres, the higher order peaks are located at $\mathrm{q} / \mathrm{q}^{*}=\sqrt{3}, \sqrt{4}$. For HCP spheres, the higher order peaks are located at $\mathrm{q} / \mathrm{q}^{*}=$ $\sqrt{3}, \sqrt{4}, \sqrt{7}, \sqrt{9}, \sqrt{12}, \sqrt{13}, \sqrt{16}$. The peak position was determined through known relationships of the interplanar spacing $(d)$ and the lattice parameters of the unit cell determined from analysis of the 2D SAXS data in Figures 5 and 7 (equations S1 and S2). 
Equation S1:

Cubic system:

$d_{h k l}=\frac{a}{\sqrt{h^{2}+k^{2}+l^{2}}}$

\section{Equation S2:}

Hexagonal system:

$$
\begin{aligned}
& d_{h k l}^{2}=\frac{1}{\left(h^{2}+k^{2}+h k\right) a *^{2}+l^{2} c *^{2}} \\
& a *=\frac{2}{a \sqrt{3}} \\
& c *=\frac{1}{c}
\end{aligned}
$$

